\title{
ACTIVITY COEFFICIENTS OF GLYCINE, DL-SERINE AND DL-VALINE IN AQUEOUS SOLUTIONS CONTAINING NITRATES AT 298.15 K
}

\author{
by \\ Chongxia Gao \\ Department of Chemical Engineering \\ McGill University, Montreal, Canada
}

A thesis submitted to the Faculty of Graduate Studies and Research in partial fulfillment of the requirements of the degree of Master of Engineering

(C) Chongxia Gao March, 2000 
National Library

of Canada

Acquisitions and Bibliographic Services

395 Wellington Street OWawn ON K1A ONA Canada
Bibliothèque nationale

du Canada

\section{Acquisitions et}

services bibliographiques

395, ne Wellington

Otawa ON K1A ONA

Canseda
The author has granted a nonexclusive licence allowing the National Library of Canada to reproduce, loan, distribute or sell copies of this thesis in microform, paper or electronic formats.

The author retains ownership of the copyright in this thesis. Neither the thesis nor substantial extracts from it may be printed or otherwise reproduced without the author's permission.
L'auteur a accordé une licence non exchusive permettant à la Bibliothèque nationale du Canada de reproduire, prêter, distribuer ou vendre des copies de cette thèse sous la forme de microfiche/film, de reproduction sur papier ou sur format électronique.

L'auteur conserve la propriété du droit d'auteur qui protège cette thèse. $\mathrm{Ni}$ la thèse ni des extraits substantiels de celle-ci ne doivent être imprimés ou autrement reproduits sans son autorisation.

\section{Canadầ}


70 My 7 amily 


\begin{abstract}
Both an electrochemical and an isopiestic methods were used to measure the mean activity coefficients of amino acids in water-electrolyte-amino acid systems. The electrochemical method used an electrochemical cell with an anion and a cation ion selective electrodes, each measured versus a double junction reference electrode. The activity coefficients of the electrolyte were obtained from the e.m.f measurements for four systems at $298.15 \mathrm{~K}$. The amino acids were glycine, DL-serine and DL-valine and the electrolyte were $\mathrm{KNO}_{3}$ and $\mathrm{NaNO}_{3}$. The isopiestic method was applied to measure the activity of water for the system water $+\mathrm{DL}$-serine $+\mathrm{KNO}_{3}$ at $298.15 \mathrm{~K}$ and the results were compared with those from electrochemical method. The activity coefficients of the amino acids in the temary systems were obtained from those of the electrolyte measured by the electrochemical method or from those of the water measured by isopiestic method. according to the cross differential relation.

Two models were used to correlate the measured data. First the excess Gibbs free energy model proposed by Khoshkbarchi and Vera (1996a) with the NRTL equation was used to correlate the activity coefficient data. A simple model derived from a modification of a more complex model based on the perturbation theory (Khoshkbarchi and Vera, 1996c) was proposed. The model was applied to correlate the activity coefficients and solubilities of amino acids in binary aqueous solutions and the activity coefficients in temary systems with satisfactory results.
\end{abstract}




\section{RÉSUMÉ}

Les méthodes électrochimique et isopiestique sont utilisées pour mesurer les coefficients d'activité des acides aminés dans une solution eau - électrolyte - acide aminé. La méthode èlectrochimique consiste en une cellule électrochimique formée d'une anode et d'une cathode, électrode selective des ions chacun étant mesurée versus d'une électrode de réfërence à double jonction. Les coefficients d'activité de l'electrolyte sont obtenus grâce à la force électromotrice (e.m.f) pour quatre systèmes à $298.15 \mathrm{~K}$. Les acides aminés étudiés étaient: giycine, DL-serine et DL-valine et les electrolytes étaient $\mathrm{KNO}_{3}$ et $\mathrm{NaNO}_{3}$. La méthode isopiestique est employée pour mesurer l'activité de l'eau dan le système eau - DL-serine - $\mathrm{KNO}_{3}$ à $298.15 \mathrm{~K}$ et les valeurs sont comparées avec la méthode électrochimique. Les coefficients d'activité des acides aminés dans le système ternaire proviennent de l'électrolyte mesuré par la méthode électrochimique, ou dans le cas de la méthode isopiestique, de l'eau mesurée, conformément à la relation de differentiation.

Les données recueillies sont corrélées par deux modèles. En premier lieu le modèle, basé sur l'excès d'énergie libre de Gibbs, proposé par Khoshkbarchi et Vera (1996 a) avec l'équation NRTL, a été employé pour corréler les résultats du coefficient d'activité. Un modèle simple dérivé d'un modèle plus complexe fondé sur la théorie de perturbation (Khoshkbarchi et Vera, 1996 c) est développé. Le modèle est utilisé avec succès pour corrèler les coefficients d'activité et les solubilités des acides aminés dans des solutions aqueuses binaires et les coefficients d'activité dans des solutions ternaires. 


\section{ACKNOWLEDGMENTS}

I am deeply indebted to Professor Juan H. Vera, my supervisor, not only for giving me the opportunity to work in his group, his support and his guidance throughout the course of this research, but also for his enthusiasm, encouragement, patience and kindness. I have leamed from him more than thermodynamics and research techniques.

I am grateful to the other Professors in our research group, Prof. M. E. Weber and Prof. J. Simandl for their interests, valuable comments and suggestions.

Thanks also go to many $\mathrm{Ph}$. D. and Master students in this group and the department: R. Dumortier, M. Husein, A. Merchant, H. Niu, K. Pehrson, A. Pradhan, Y.O. Shin. V. Taghikhani. E. Wong. Their help, encouragement and enthusiasm made my stay in this group an interesting and joyful experience.

Finally, I want to express my gratitude to the Chemical Engineering Department. Many people in the department gave me a lot of help during my research work. 


\section{TABLE OF CONTENTS}

Page

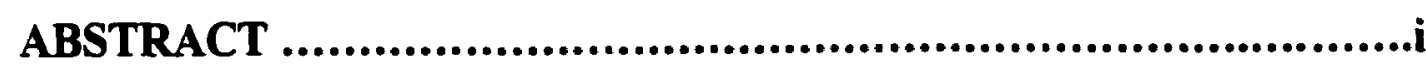

RESUME.................................................................ii

ACKNOWLEDGMENTS.................................................iii

TABLE OF CONTENTS ...............................................iv

LIST OF FIGURES ...................................................vi

LIST OF TABLES.......................................................vii

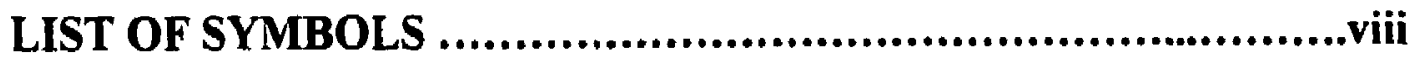

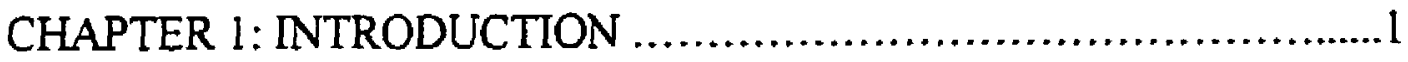

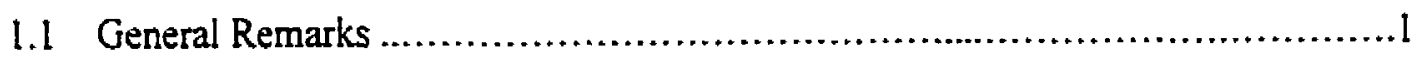

1.2 Chemical Structure of Amino Acids .............................................

1.3 Experimental Measurement of Activity Coefficients ..............................

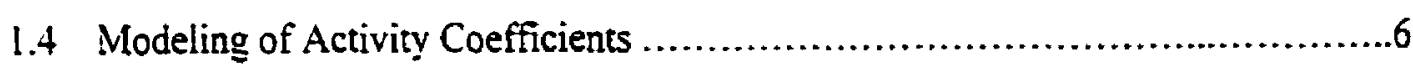

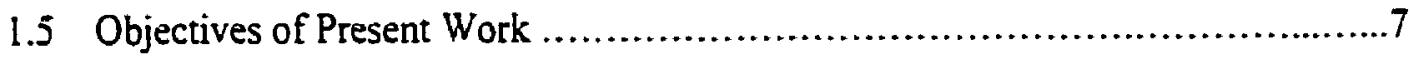

CHAPTER 2: ELECTROCHEMICAL MEASUREMENT OF ACTIVITY COEFFICIENTS OF AMINO ACIDS IN AQUEOUS ELECTROLYTE SOLUTIONS .................................................. 10

2.1 Theoretical Basis of the Measurements .............................................10

2.2 Experimental Set Up, Materials and Methods for Measuring the Activity Coefficients of Electrolytes in Aqueous Solutions .................................12

2.3 Experimental Results and Discussions ........................................15

CHAPTER 3: MEASUREMENT OF ACTIVITY COEFFICIENT USING ISOPIESTIC METHOD ............................................26 


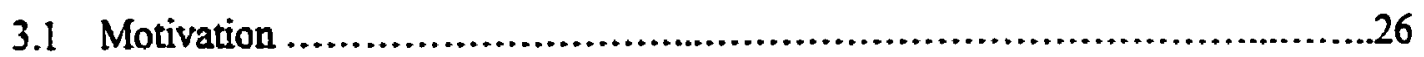

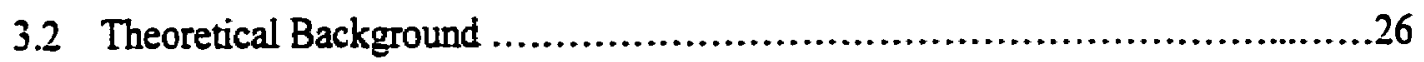

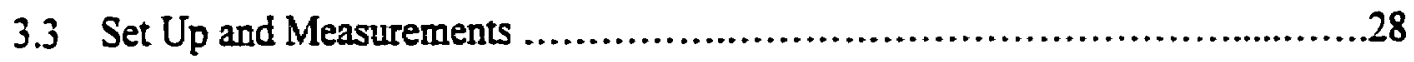

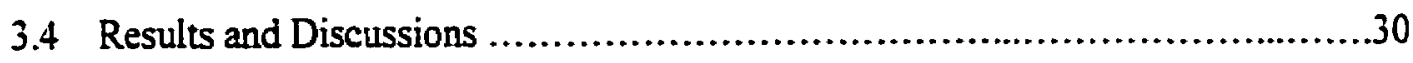

3.5 Comparison with the Electrochemical Method ..................................32

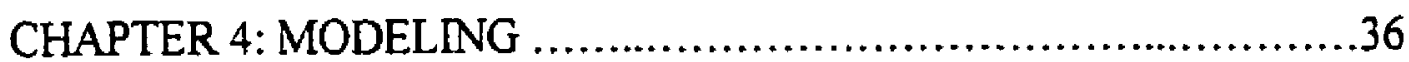

4.I Gibbs Free Energy Model with NRTL Equation ......................................36

4.2 A New Model Based on a Simplified Perturbation Theory ..........................38

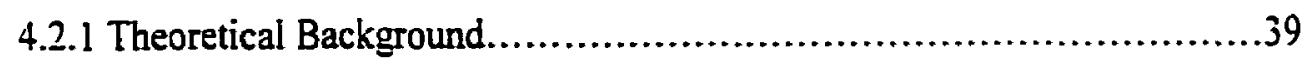

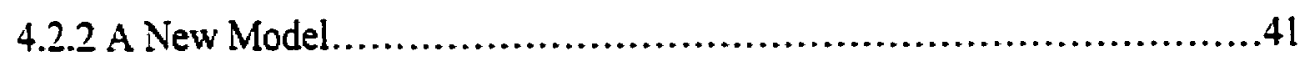

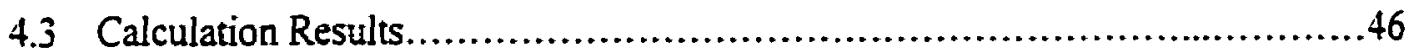

4.3.1 Binary systems.........................................................46

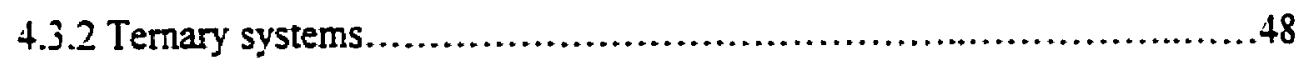

4.4 Modeling the Solubility of Amino Acid in Water...................................51

CHAPTER 5: CONCLUSIONS, CONTRIBUTIONS TO KNOWLEDGE AND SUGGESTIONS FOR FUTURE WORK..........................55

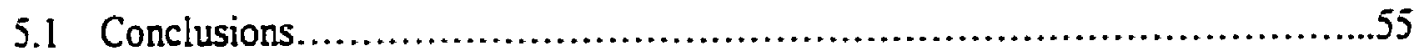

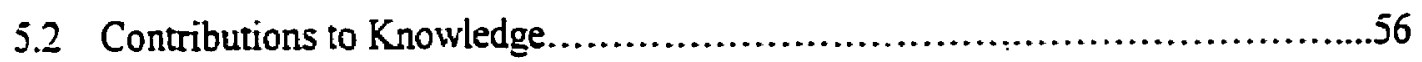

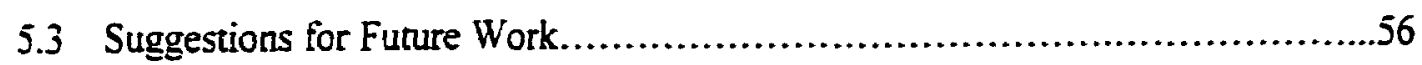

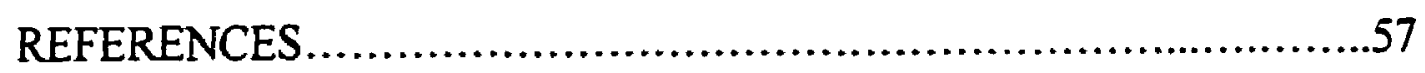

APPENDICES ......................................................62

A $\Delta E$ data by Electrochemical Method..................................................62

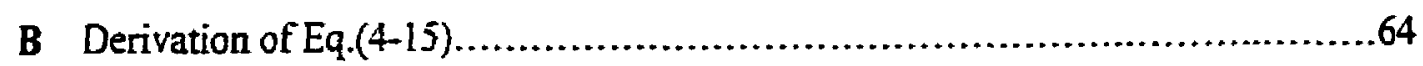

C Derivation of the Perturbation Term for Mixtures......................................65

D The Cross Differential Relation for the Perturbation Theory ..............................66 


\section{LIST OF FIGURES}

Figure 1.1 Structure of amino acids. (a) molecular structure of $\alpha$-amino acid

(b) structure of the zwitterion form. .2

Figure 2.1 Schematic view of the set up used for measurement of the mean ionic activity coefficient of an electrolyte in aqueous solutions.....

Figure 2.2 Effect of concentrations of $\mathrm{NaNO}_{3}$ and DL-serine, in aqueous solutions at $298.2 \mathrm{~K}$, on the ratios $\gamma_{ \pm}^{(2)} / \gamma_{ \pm}^{(1)} ; \gamma_{t}^{(?)} / \gamma_{t}^{(1)}$. Dots: experimental points; curves: equations (2-10), (2-13), respectively.

Figure 2.3 Effect of concentrations of $\mathrm{KNO}_{3}$ and $\mathrm{DL}$-serine, in aqueous solutions at $298.2 \mathrm{~K}$, on the ratios $\gamma_{=}^{(2)} / \gamma_{=}^{(1)} ; \gamma_{A}^{(2)} / \gamma_{A}^{(1)}$. Dots: experimental points; curves: equations $(2-10),(2-13)$, respectively 21

Figure 2.4 Effect of concentrations of $\mathrm{NaNO}_{3}$ and $\mathrm{DL}$-valine, in aqueous solutions at $298.2 \mathrm{~K}$, on the ratios $\gamma_{ \pm}^{(2)} / \gamma_{ \pm}^{(1)} ; \gamma_{+}^{(2)} / \gamma_{+}^{(1)}$. Dots: experimental points; curves: equations $(2-10),(2-13)$, respectively .23

Figure 2.5 Re-plot of $\gamma_{A}^{(2)} / \gamma_{A}^{(1)}$ as a function of $m_{. t}$ for fixed values of $m_{S}$ 24

Figure 2.6 Effect of concentrations of $\mathrm{KNO}_{3}$ and glycine, in aqueous solutions at $298.2 \mathrm{~K}$, on the ratios $\gamma_{ \pm}^{(2)} / \gamma_{ \pm}^{(1)} ; \gamma_{A}^{(2)} / \gamma_{A}^{(1)}$. Dots: experimental points; curves: equations $(2-10),(2-13)$, respectively. .25

Figure 3.1 A view of isopiestic set up ...........................................30

Figure 3.2 Comparison of activity coefficients of DL-serine by two methods.............35

Figure 3.3 Comparison of mean ionic activity coefficient by two methods...............35

Figure 4.1 Correlation results for activity coefficients of amino acids in binary aqueous solutions.

Figure 4.2 Correlation results by the simplified perturbation model for the mean activity coefficient of $\mathrm{KNO}_{3}$ in temary systems $\left(\mathrm{KNO}_{3}+\right.$ glycine $\left.+\mathrm{H}_{2} \mathrm{O}\right) \ldots \ldots \ldots \ldots . . .50$

Figure 4.3 Correlation results for solubility of amino acids in $\mathrm{H}_{2} \mathrm{O}$. .54 


\section{LIST OF TABLES}

Table 1.1: Systems for which activity coefficients of amino acids in aqueous electrolyte

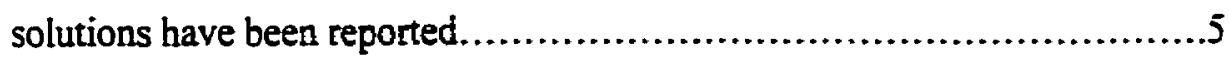

Table 1.2: Systems to be measured..................................................

Table 1.3 Chemical structure of the amino acids used in this work........................8

Table 2.1 Experimental results for $\mathrm{NaNO}_{3}+\mathrm{DL}$-serine system.........................16

Table 2.2 Experimental results for $\mathrm{NaNO}_{3}+\mathrm{DL}$-valine system ......................16

Table 2.3 Experimental results for $\mathrm{KNO}_{3}+\mathrm{DL}$-serine system .......................17

Table 2.4 Experimental results for $\mathrm{KNO}_{3}+$ glycine system.............................17

Table 2.5 Pooled standard deviation of measured ratio $\gamma_{ \pm}^{(2)} / \gamma_{=}^{(1)} \ldots \ldots \ldots \ldots \ldots \ldots \ldots . . . . . .18$

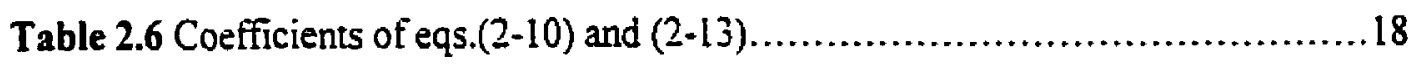

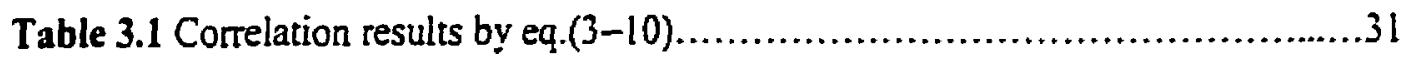

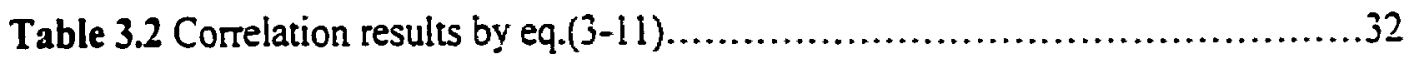

Table 3.2 Measured data from isopiestic method........................................34

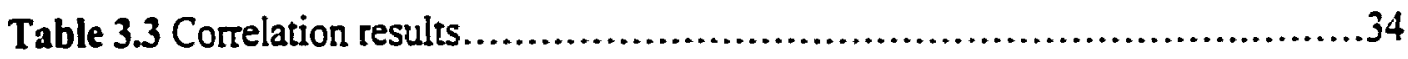

Table 4.1 Values of pure component parameters of ions and electrolytes...................45

Table 4.2 Calculation results for activity coefficients of amino acids.....................46

Table 4.3 Results for ternary systems by Gibbs free energy model..........................48

Table 4.4 Results for temary systems by perturbation model.............................49

Table 4-5 Calculation results for solubility of amino acids..............................53

Table A.1 $\Delta \mathrm{E}$ data for $\mathrm{NaNO}_{3}+\mathrm{DL}$-serine $+\mathrm{H}_{2} \mathrm{O}$ system...........................58

Table A.2 $\triangle \mathrm{E}$ data for $\mathrm{NaNO}_{3}+\mathrm{DL}$-valine $+\mathrm{H}_{2} \mathrm{O}$ system .........................58

Table A.3 $\Delta \mathrm{E}$ data for $\mathrm{KNO}_{3}+\mathrm{DL}$-serine $+\mathrm{H}_{2} \mathrm{O}$ system ...........................59

Table A.4 $\Delta \mathrm{E}$ data for $\mathrm{KNO}_{3}+$ glycine $+\mathrm{H}_{2} \mathrm{O}$ system...............................59 


\section{LIST OF SYMBOLS}

a

A

AAD

b, c, d

B

$\mathrm{B}_{\mathrm{i}}$

c

$\mathrm{C}_{\mathrm{l}}$

D

e.m.f.

E.

E.

$E_{+}^{\text {ISE }}$

$E_{+}^{0}$

E.

$E^{\text {LSE }}$

$E^{J}$

$E^{\operatorname{Ref}}$

$\Delta E^{(1)}$

$\Delta E^{(2)}$

f

G

$\mathrm{G}_{\mathrm{ij}}$

$g(r)$

$\Delta \mathrm{h}$

ISE
Activity

Constant in eq. $(3-10)$

Average absolute deviation

Parameters in eq. (3-11)

Constant, 0.2

Parameters in eq. $(3-10), i=1,3$

Total number of components

Adjustable parameters in eqs. $(2-10),(3-7), i=0,6$

Dipole moment

Electromotive force

Potential of the cation ion selective electrode

Potential of the anion ion selective electrode

Intemal potential of the cation ion selective electrode

Standard state potential of the cation ion selective electrode

Standard state potential of the anion ion selective electrode

Internal potential of the anion ion selective electrode

Junction potential

Reference electrode potential

Potential difference in electrochemical cell in the presence of electrolyte and in the absence of amino acid

Potential difference in electrochemical cell in the presence of both electrolyte and amino acid

Faraday number

Fugacity

Gibbs free energy

Binary interaction energy function in the NRTL model

Radial distribution function

Enthalpy change

Ion selective electrode 


\begin{tabular}{|c|c|}
\hline k & Boltzmann constant $\left(1.381 \times 10^{-23} \mathrm{~J} \mathrm{~K}^{-1}\right)$ \\
\hline m & Concentration in molality unit \\
\hline $\mathrm{m}_{\mathrm{A}}$ & Molality of amino acid \\
\hline $\mathrm{m}_{\mathrm{S}}$ & Molality of electrolyte \\
\hline $\mathrm{m}_{+}$ & Molality of cation \\
\hline $\mathrm{m}-$ & Molality of anion \\
\hline M & Molecular weight \\
\hline $\mathrm{n}$ & Number of moles \\
\hline$n_{0}$ & Number of data points \\
\hline $\mathrm{N}$ & Number of molecules \\
\hline $\mathrm{N}_{\mathrm{a}}$ & Avogadro number $\left(6.02252 \times 10^{23}\right)$ \\
\hline O.F. & Objective function \\
\hline r.m.s.d. & Root mean square deviation \\
\hline $\mathrm{r}$ & Intermolecular or interionic distance \\
\hline $\mathrm{R}$ & Universal gas constant \\
\hline$\Delta s$ & Entropy change \\
\hline S & Slope of electrode potential \\
\hline $\mathbf{S}$ & Solubility of amino acid in water \\
\hline s.e.e & Standard error of estimate \\
\hline $\mathrm{T}$ & Absolute temperature \\
\hline u & Intermolecular potential \\
\hline V & Volume \\
\hline$x$ & Mole fraction \\
\hline $\mathrm{Z}$ & Charge number of cation \\
\hline Z- & Charge number of anion \\
\hline
\end{tabular}

Greek letters

$\alpha$ Parameter of the NRTL model ( 0.3$)$

$\bar{\alpha} \quad$ Polarizability

$\eta \quad$ Quantity defined by eq.(4- 11$)$ 
$\delta^{(0)}, \delta^{(1)} \quad$ Parameters in mixing rule eq.(4-27)

$\Delta \quad$ Quantity defined by eq. (3-6)

$\gamma \quad$ Activity coefficient

$\gamma_{\mathrm{A}} \quad$ Activity coefficient of amino acid

ys Activity coefficient of electrolyte

$\gamma_{+} \quad$ Activity coefficient of cation

$r_{-} \quad$ Activity coefficient of anion

$\gamma_{ \pm} \quad$ Mean ionic activity coefficient of electrolyte

$\gamma_{ \pm}$(i) Mean ionic activity coefficient of electrolyte in electrochemical cell in the absence of amino acid

$\gamma_{ \pm}^{(2)} \quad$ Mean ionic activity coefficient of electrolyte in electrochemical cell in the presence of amino acid

Depth of potential well, molecular energy parameter

$\varepsilon_{0} \quad$ Permitivity of the vacuum

$\varepsilon_{\mathrm{r}} \quad$ Relative dielectric constant

$\mu \quad$ Chemical potential

$v \quad$ Stoichiometric number of electrolyte, $\left(v_{+}+v\right)$

$v+\quad$ Stoichiometric number of cations

$v$ Stoichiometric number of anions

$\rho \quad$ Number density

$\sigma \quad$ Molecular diameter, size parameter

$\tau_{i j} \quad$ Binary energy parameter between species $i$ and $j$ in the NRTL model

$\phi \quad$ Osmotic coefficient

\section{Superscripts}

0

Standard state

Cal

Calculated

E Excess free energy

$\exp \quad$ Experimental 
HS

ISE

$\mathrm{K}-\mathrm{V}$

L

L-J

LR

Per

Ref

$S$

SR

Subscripts

$\begin{array}{ll}\text { A } & \text { Amino acid } \\ \mathrm{e} & \text { Effective hard sphere diameter } \\ \mathrm{i}, \mathrm{j}, \mathrm{k} & \text { Species } \mathrm{i} . \mathrm{j}, \mathrm{k} \\ \mathrm{W} & \text { Water } \\ \mathrm{S} & \text { Electrolyte } \\ \dot{-} & \text { Cation } \\ - & \text { Anion } \\ \pm & \text { Mean ionic }\end{array}$

Hard sphere

Ion selective electrode

$\mathrm{K}-\mathrm{V}$ model

Liquid phase

Lennard-Jones

Long range interactions term

Perturbed term

Reference term

Solid phase

Short range interactions term

Mean ionic 


\section{CHAPTER 1: INTRODUCTION}

\subsection{General Remarks}

The industrial scale production of biochemicals is of potential interests for the chemical, pharmaceutical and food industries. The separation and concentration process of biomolecules is one of the economically important stages in their production processes. As amino acids are the simplest biomolecules and the building blocks of other biomolecules such as peptides and proteins. a knowledge of the thermodynamic properties of amino acids in aqueous electrolyte solutions is a first step towards the rational design of equilibrium-based separation processes. In addition, such information is useful for the understanding of the molecular interactions in these systems.

The experimental and theoretical research on the equilibrium properties of amino acid solutions have attracted attention in recent years. The chemical engineering thermodynamics research group at McGill University has published a series of articles on separation processes and themodynamic properties of amino acid in aqueous electrolyte solutions. A new electrochemical method was developed for the measurement of activity coefficients of amino acids (Khoshkbarchi and Vera, 1996a,b). Data of activity coefficients and solubilities were published for various systems and some theoretical models were proposed for these properties (Khoshkbarchi and Vera, 1996a, b, c. d, e; Khoshkbarchi and Vera, 1997; Soto-Campos et al., 1997a,b, 1998; Pradhan and Vera, 1998). This work is a continuation of research work carried out by this research group.

\subsection{Chemical Structure of Amino Acids}

The physico-chemical behavior of amino acids in aqueous electrolyte solutions is the result of their special molecular structure. As shown in Fig.1 (a), an $\alpha$-amino acid molecule is composed of three parts: a terminal carboxyl group $(-\mathrm{COOH})$, an amino 
group $\left(-\mathrm{NH}_{2}\right)$, and a hydrocarbon backbone $(-\mathrm{R})$ with variable length, connected together by a central carbon atom (called $\alpha$ carbon, $\mathrm{C} \alpha$ ). If the amino group is attached to the carbon next to the $\alpha$ carbon of the alkyl chain $-R$, the amino acid is called $\beta$-amino acid. Thus depending on the location of the amino group in the hydrocarbon backbone of the amino acid, they are classified as $\alpha, \beta, \gamma, \delta$, $\varepsilon$, etc. amino acids.

In aqueous solutions in the neutral $\mathrm{pH}$ range, amino acids form a zwitterion (zwitter $=$ two) resulting from the transfer of a proton from the carboxyl group to the amino group. Therefore, an amino acid molecule possesses, at the same time, a negative and a positive charge and this form is called a zwitterion. The electric field surrounding these charged ions gives rise to important interactions. The structure of the zwitterion is shown in Fig. 1.1 (b).
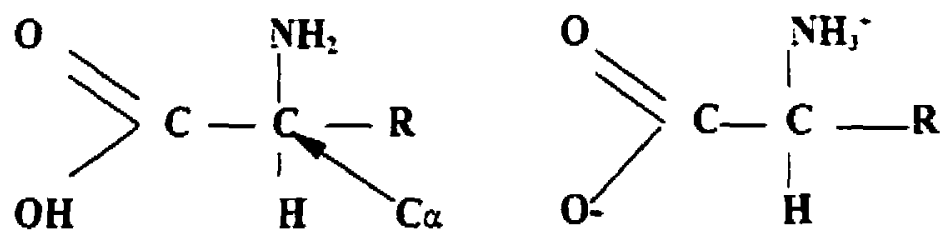

Figure 1.1 Structure of amino acids. (a) molecular structure of $\alpha$-amino acid (b) structure of the zwitterion form.

The following reactions may take place when an amino acid is dissolved in water at different $\mathrm{pH}$ values:

(a) $\mathrm{NH}_{2} \mathrm{RCOOH} \Leftrightarrow \mathrm{NH}_{3}{ }^{+} \mathrm{RCOO}$

(b) $\mathrm{NH}_{3}{ }^{+} \mathrm{RCOO}^{-}+\mathrm{H}^{+} \Leftrightarrow \mathrm{NH}^{+}{ }_{3} \mathrm{RCOOH}$

(c) $\mathrm{NH}_{3}{ }^{+} \mathrm{RCOO}{ }^{-} \Leftrightarrow \mathrm{H}^{+}+\mathrm{NH}_{2} \mathrm{RCOO}^{-}$ 
In aqueous solution at neutral $\mathrm{pH}$, the amino acid molecules are in their zwitterionic form and the concentration of anionic and cationic forms are negligible. At low $\mathrm{pH}$, the amino molecules are in cationic form, $\mathrm{NH}_{3}{ }^{+} \mathrm{ROOH}$, and at high $\mathrm{pH}$ they are in anionic form, $\mathrm{NH}_{2} \mathrm{RCOO}$.

\subsection{Experimental Measurement of Activity Coefficients}

There are two types of methods commonly used for measuring the activity coefficients of amino acid in aqueous electrolyte solutions. One is the electrochemical method and the other is the isopiestic method. Both methods are indirect, in the sense that the activity coefficient of the amino acid is obtained by measuring either the mean ionic activity coefficient of the electrolyte or the osmotic coefficient of the solution.

\section{Electrochemical method}

The electrochemical method has been widely used for measuring the activity coefficients of electrolytes in aqueous solutions. In some measurements of activity coefficients of amino acid-electrolyte-water systems using electrochemical method (Kelley and Lilley, 1978; Rodriguez-Raposo et al., 1994), only one ion selective electrode (usually a cation ion selective electrode) versus a reference electrode, was used to measure the mean ionic activity coefficients of electrolyte in the presence of another solute (i.e., amino acid). The drawbacks of this method have been discussed by Khoshkbarchi and Vera (1996a, b). A new method was proposed by Khoshkbarchi and Vera $(1996 \mathrm{a}, \mathrm{b})$, in which two ISEs with the same reference electrode were used so as to eliminate the shortcomings of the single ISE method and obtain more reliable results. This latter method, using two IESs, will be used in this work. The major advantage of this method is that the measurement takes a very short time in comparison with the isopiestic method. Its disadvantage is that the measurements are limited by the range of applicability of the electrodes. 


\section{Isopiestic Method:}

The isopiestic method was proposed more than a century ago and modified by Sinclair (1933). A detailed example of well designed apparatus was given by Scatchard et al. (1938). In 50's, many researchers used this methods (Robinson and Stokes, 1959). Two vessels were used in the measurements and the time needed for reaching equilibrium was very long. Recently, improved isopiestic methods were developed: Thiessen and Wilson (1987) used a three vessel apparatus; Ochs et al. (1990) used an apparatus with nine vessels, and a similar method was used by Lin et al. (1996) and by Park and Englezos (1998).

The major advantage of this method is that it can be used over the whole range of concentration. The main disadvantage is that it is time consuming, though an apparanus with multiple vessels may partially solve the problem.

In this work, an apparatus which is similar to the design used by Park and Englezos (1998) is used to measure the osmotic coefficients of aqueous electrolyte solutions containing amino acids. The results obtained are compared with those obtained by the electrochemical method for the system of DL-serine- $\mathrm{KNO}_{3}-\mathrm{H}_{2} \mathrm{O}$.

\section{Systems studied}

Table 1.1 lists the systems of amino acid-electrolyte -water for which activity coefficients have been reported according to our knowledge. 
Table 1.1 Systems for which activity coefficients of amino acids in aqueous electrolyte solutions have been reported

\begin{tabular}{|c|c|c|c|}
\hline Amino acid & Electrolyte & Method $^{3}$ & ${ }^{a}$ References $^{b}$ \\
\hline glycine & $\mathrm{NaCl}$ & $E C, \mathbb{P}$ & {$[1],[9],[13]$} \\
\hline DL-alanine & $\mathrm{NaCl}$ & $\mathrm{EC}$ & {$[1]$} \\
\hline DL-valine & $\mathrm{NaCl}$ & EC & [2] \\
\hline DL-serine & $\mathrm{NaCl}$ & $\mathrm{EC}$ & [3] \\
\hline glycine & $\mathrm{KCl}$ & $\mathrm{EC}$ & [4] \\
\hline DL-alanine & $\mathrm{KCl}$ & $E C$ & [5] \\
\hline DL-valine & $\mathrm{KCl}$ & EC & [6] \\
\hline DL-serine & $\mathrm{KCl}$ & EC & {$[3]$} \\
\hline glycine & $\mathrm{NaNO}_{3}$ & EC & [7] \\
\hline DL-alanine & $\mathrm{NaNO}_{3}$ & EC & {$[5]$} \\
\hline DL-methionine & $\mathrm{NaCl}$ & $E C$ & [7] \\
\hline DL-threonine & $\mathrm{NaCl}$ & $E C$ & [8] \\
\hline DL-threonine & $\mathrm{NaNO}_{3}$ & $E C$ & [8] \\
\hline$\beta$-alanine & $\mathrm{NaCl}$ & $\mathbb{I P}$ & {$[10]$} \\
\hline$\gamma$-aminobutyric acid & d $\mathrm{NaCl}$ & $\mathbb{P}$ & {$[10]$} \\
\hline$\gamma$-aminocaproic acid & id $\mathrm{NaCl}$ & IP & {$[10]$} \\
\hline L- $\alpha$-alanine & $\mathrm{NaCl}$ & IP & {$[11]$} \\
\hline glycine & $\mathrm{CaCl}_{2}$ & $\mathrm{EC}$ & {$[12]$} \\
\hline$\beta$-alanine & $\mathrm{CaCl}_{2}$ & EC & {$[12]$} \\
\hline$\gamma$-aminobutyric acid & d $\mathrm{CaCl}_{2}$ & EC & [12] \\
\hline$\varepsilon$-aminocaproic acid & id $\mathrm{CaCl}_{2}$ & $\mathrm{EC}$ & {$[12]$} \\
\hline
\end{tabular}

a, EC: electrochemical method; IP: isopiestic method; $b$, see next page. 
[1] Khoshkbarchi and Vera. 1996b; [2] Khoshkbarchi and Vera, [996a; [3] Khoshkbarchi et al., J. 1997; [4] Bower and Robinson, 1965; [5] Soto -Campos et al., 1998; [6] Khoshkbarchi and Vera, 1996c; [7] Soto-Campos et al., 1997a: [8] Soto-Campos et al., 1997b; [9] Rodriguez-Raposo et al., 1994; [10] Schrier and Robinson, 1971; [11] Schrier and Robinson, 1974; [12] Briggs et al., 1974; [13] Phang and Steel, 1974.

Previous results show that the effect of salts on the activity of an amino acid is considerable. In some cases adding salt into the solution will increase the activity coefficient of the amino acid, while in other cases the activity coefficient of the amino acid will decrease as salt is added.

\subsection{Modeling of Activity Coefficients}

The modeling of activity coefficients is important since experimental methods only give data at discrete values of concentration and temperature. A reliable model can provide useful correlation and even prediction of results over a wide range of conditions based on a few experimental values.

Many theoretical or semi-empirical models have been proposed in literanure for the systems containing electrolytes and amino acids. For example, Khoshkbarchi and Vera (1996a) proposed a Gibbs free energy model which used the Wilson or the NRTL equation for the short range interaction contributions. The same authors have also proposed a model based on the perturbation theory (Khoshkbarchi and Vera, 1996c,d). In this work, the Gibbs free energy model with the NRTL equation will be used to correlate the activity coefficient data for the ternary systems measured. In addition, a new simplified model based on the perturbation theory will be used to represent the activity coefficient of amino acids in both binary and ternary systems. 


\subsection{Objectives of the Present Work}

The objectives of this work are the following:

(Ia) To measure the activity coefficients of the electrolyte and calculate the activity coefficients of the amino acid at $298.15 \mathrm{~K}$ for the four systems listed in Table 1.2.

Table 1.2 Systems to be measured

Amino acid Electrolyte Amino acid molality Electrolyte molality Method

\begin{tabular}{llllll}
\hline 1 & glycine & $\mathrm{KNO}_{3}$ & $0.05<\mathrm{m}_{\mathrm{A}}<2.50$ & $0.1<\mathrm{m}_{\mathrm{S}}<0.7$ & EC \\
2 & DL-serine & $\mathrm{KNO}_{3}$ & $0.05<\mathrm{m}_{\mathrm{A}}<0.40$ & $0.1<\mathrm{m}_{\mathrm{S}}<0.7$ & EC. IP \\
3 & DL-valine $\mathrm{NaNO}_{3}$ & $0.05<\mathrm{m}_{\mathrm{A}}<0.50$ & $0.1<\mathrm{m}_{\mathrm{S}}<1.0$ & EC \\
4 & DL-serine $\mathrm{NaNO}_{3}$ & $0.05<\mathrm{m}_{\mathrm{A}}<0.40$ & $0.1<\mathrm{m}_{\mathrm{S}}<1.0$ & EC \\
\hline
\end{tabular}

These ranges of molalities were chosen so to be within the concentration range in which the ISE electrodes are reliable and also to be below the solubility limit of the electrolyte and the amino acid in the system. The electrochemical method will be used in all cases.

(lb) To present a comparison of the results for DL-serine $+\mathrm{KNO}_{3}$ system obtained from the electrochemical and isopiestic methods.

The chemical structure of the amino acids used in this work are given by Table 1.3. 
Table 1.3 Chemical structure of the amino acids used in this work<smiles>CC(C)C(N)C(=O)O</smiles>

(2). To present a summary of the salt effects on the activities of amino acids in the systems measured and explain the effects based on the interactions between ions and zwitterions and their structures.

(3) To model the experimental data using the Gibbs free energy model proposed by Khoshkbarchi and Vera (1996a).

(4) To use a simplified model based on the perturbation theory to correlate activity coefficients of amino acids in both binary and ternary systems. 
(5) To use the new activity coefficient model for the correlation of solubility of amino acids in water.

The rest of the thesis is organized as follows: Chapter 2 presents the principle of the measurement of activity coefficients using the electrochemical method, the experimental results obtained in this work and discussion. Chapter 3 presents the principle of the measurement of activity coefficients using the isopiestic method, the experimental results obtained in this work and discussion. Chapter 4 gives the derivation of a new model and results of the modeling using two approaches and discussion. Chapter 5 includes a general discussion of the work, the main contributions and suggestions for future work. 


\section{CHAPTER 2: ELECTROCHEMICAL MEASUREMENT OF ACTIVITY COEFFICIENTS OF AMINO ACDS IN AQUEOUS ELECTROLYTE SOLUTIONS}

\subsection{Theoretical Basis of the Measurements}

Among the various electrochemical methods, electrochemical cells with ion selective electrodes (ISE) are an efficient tool for the measurements of thermodynamic properties of electrolyte solutions (Haghtalab and Vera, 1991). The electrochemical method has proved to give reliable results for the activities of solutes in electrolyte solutions (Kelley and Lilley, 1978; Rodriguez-Raposo et al., 1994; Khoshkbarchi and Vera, 1996a, b).

The activity coefficients of the solute (amino acid) are obtained from measurements of the electrochemical potential (e.m.f) in electrochemical cells of the type:

ISE $\mid$ electrolyte + amino acid + water $\mid$ reference electrode

It is also necessary to measure the e.m. $\mathrm{f}$ in an electrolyte aqueous solution without amino acid for calibration purposes. For the electrochemical cell:

ISE | electrolyte + water | reference electrode

the relation between e.m.f. of a cation selective electrode and activity coefficients of the cation is given by the Nerst equation:

$$
E_{+}=E_{+}^{0}+\frac{R T}{z_{+} F} \ln \left(m_{+} \gamma_{+}\right)
$$




$$
E_{-}=E_{-}^{0}-\frac{R T}{z_{-} F} \ln \left(m_{-} \gamma_{-}\right)
$$

where $R$ is the gas constant. $T$, temperature, $z$, the charge number, $F$ the Faraday constant. $m$ the molality of the ion, $y$ the activity coefficient, and $E$ the e.m.f. The terms $E_{-}^{0}$ and $E^{0}$. are combinations of junction potential $\left(E^{J}\right)$, reference electrode potential $\left(E^{\text {Ref }}\right)$, and the ion selective electrode potential $\left(E^{I S E}\right)$ :

$$
\begin{aligned}
& E_{+}^{0}=E^{\text {Ref }}+E^{J}+E_{+}^{I S E} \\
& E_{-}^{0}=E^{\text {Ref }}+E^{J}+E_{-}^{I S E}
\end{aligned}
$$

Combining eqs.(2-1), (2-2) and after rearrangement, we have

$$
E_{-}-E_{-}=\left(E_{-}^{0}-E_{-}^{0}\right)+S \ln \left(m_{s} \gamma_{s}\right)
$$

where $m_{S}$ is the molality of salt and the mean ionic activity coefficient of the electrolyte is defined as

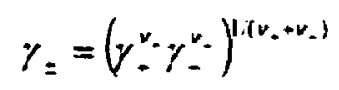

In eq.(2-6), $v_{-}$and $v_{-}$are the stoichiometric numbers of moles of cation and anion produced per mole of electrolyte. In eq.(2-5) the slope $S$ is a function of temperature and should be calculated from linear fitting of the values of $\Delta E$ versus $\ln \left(m_{s} \gamma_{ \pm}\right)$from a system for which activity coefficients of electrolyte are known. Applying eq.(2.5) to systems electrolyte + water (superscript 1 ) and amino acid + electrolyte + water (superscript 2 ) at the same molality of the electrolyte:

$$
\begin{aligned}
& \Delta E^{(1)}=E^{0}+S \ln \left(m_{s} \gamma_{=}^{(l)}\right) \\
& \Delta E^{(2)}=E^{0}+S \ln \left(m_{s} \gamma_{ \pm}^{(2)}\right)
\end{aligned}
$$


then

$$
\ln \left(\frac{\gamma_{ \pm}^{(2)}}{\gamma_{ \pm}^{(1)}}\right)=\frac{\Delta E^{(2)}-\Delta E^{(1)}}{S}
$$

Eq.(2.9) is used to calculate the mean ionic activity coefficient of the electrolyte in aqueous solutions containing an amino acid. The values of $\gamma_{x}$ in binary electrolyte + water systems are obtained from the literature.

In this work the differences of e.m.f., $\Delta E^{(I)}$ and $\Delta E^{(2)}$ in aqueous solutions have been measured using the method proposed by Khoshkbarchi and Vera (1996a) due to its advantages over the traditional method (see, e.g., Briggs et al., 1974). The electrochemical cell used is as follows:

Cation ISE | electrolyte $\left(\mathrm{m}_{\mathbf{S}}\right)+$ solute $\left(\mathrm{m}_{\mathrm{A}}\right)+$ water $\mid$ reference electrode

Anion ISE | electrolyte $\left(m_{S}\right)+$ solute $\left(m_{A}\right) \div$ water $\mid$ reference electrode

The measured activity coefficients of the electrolytes are then used to evaluate the activity coefficients of the amino acid, as discussed below.

\subsection{Experimental Set Up, Materials and Methods for Measuring the Activity Coefficients of Electrolytes in Aqueous Solutions}

The experimental set up used in this work is illustrated in Figure 2.1. Basically it consists of a cation and an anion selective electrodes with a double junction reference electrode. A Ross sodium ion selective electrode, glass body model 84-11, and a doublejunction electrode, model 13-620-46, were obtained from Orion (Boston, MA). A Potassium ion selective electrode, polymer body, model 93-19, was obtained from Radiometer (Kopenhagen, Denmark). A nitrate ion electrode, polymer body, model 9300BN was obtained from Orion. An Oakton pH/TSE meter (WD-35616-00, Singapore) with a resolution of $\pm 0.1 \mathrm{mV}$ was used to monitor the e.m.f. measurements. 
Chapter 2. ELECTROCHEMICAL MEASUREMENT OF ACTIVITY COEFFICIENTS OF ALIINO ACIDS...

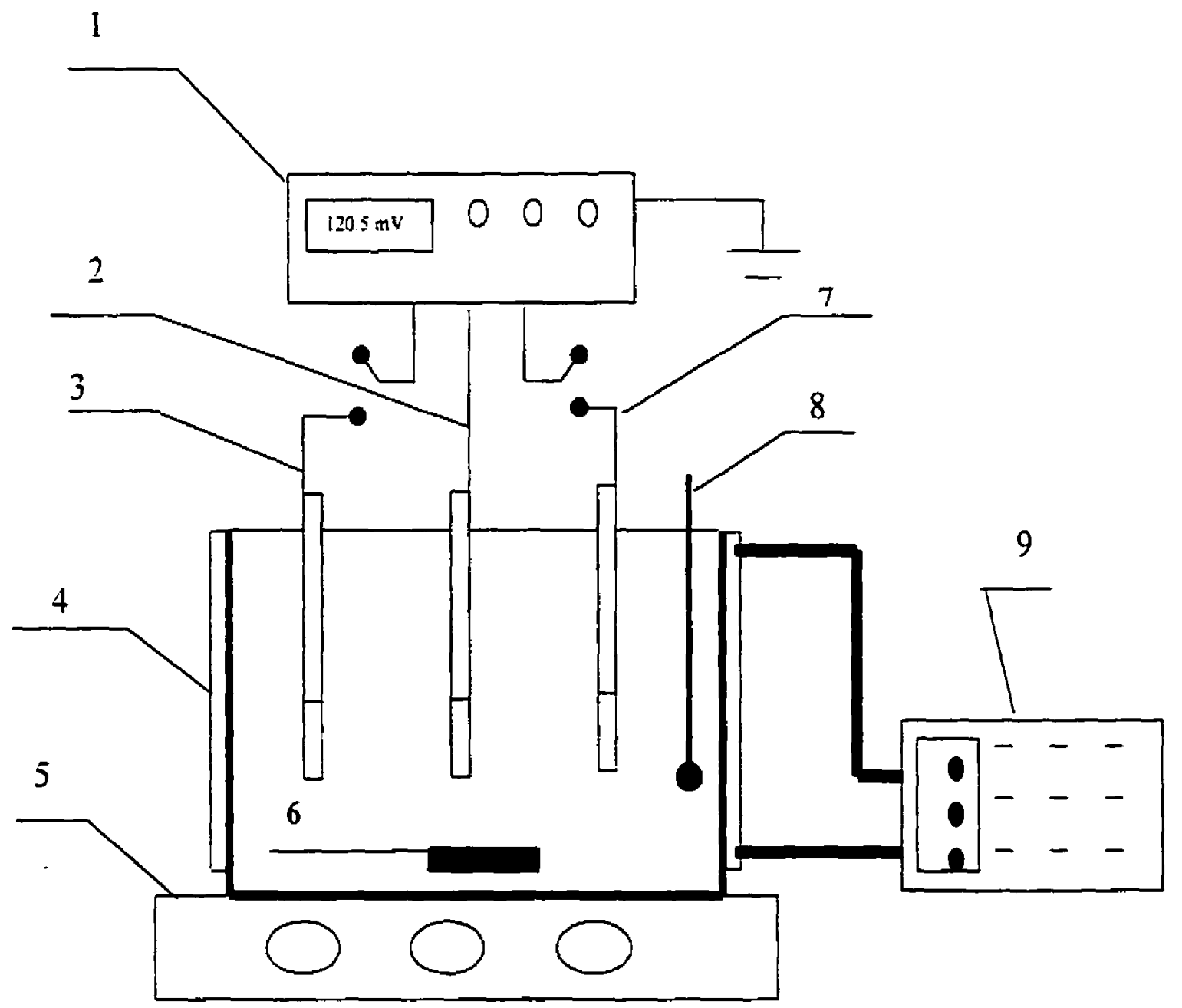

Figure 2.1 Schematic view of the set up used for measurement of the mean ionic activity coefficient of an electrolyte in aqueous solutions. 1: millivoltmeter; 2: reference electrode; 3: cation ISE; 4: cell; 5: magnetic stirrer; 6: magnet; 7: anion ISE; 8: thermometer; 9:thermostatic bath. 
The chemicals used were obtained from A\&C American Chemicals LTD (Montreal). The purity of salts used $\left(\mathrm{NaNO}_{3}, \mathrm{KNO}_{3}\right)$ was $99.9 \%$ and those of Glycine, DL- valine, and DL-serine were $98-99 \%$.

The salts were over-dried at $110^{\circ} \mathrm{C}$ for 72 hours prior to use. The amino acids were used as received. The electrodes were stored and conditioned according to the manufacturer's instructions.

\section{Experimental procedure}

The aqueous solutions of electrolytes at desired molality were prepared and solid amino acids were then subsequently added. Deionized water with a conductivity less than $0.8 \mu \mathrm{S} / \mathrm{cm}$ was used in all experiments. Water, electrolyte and amino acid were weighed. The compositions of the initial solutions were accurate to within $\pm 0.01 \mathrm{wt} \%$. The volume of the solution was about $200 \mathrm{ml}$. The electrode was carefully prepared according to the instruction manual. The temperature was kept at $298.15 \pm 0.05 \mathrm{~K}$ by using a jacketed glass beaker with circulating water. To minimize the concentration and temperature gradients, a magnetic stirrer was employed in the beaker. A thermometer with a reading accuracy to within $\pm 0.05^{\circ} \mathrm{C}$ was placed in the jacket beaker. The e.m.f. of both the cation and anion ion selective electrodes were measured against a double junction reference electrode immersed in the solution in the jacketed beaker. The potentiometer readings were recorded only when the drift of the response was less than $0.1 \mathrm{mV}$ in about 10 minutes. The readings for the cation and the anion electrodes were recorded simultaneously. All instruments were grounded prior to and during the experiments.

\subsection{Experimental Results and Discussions}

The experimental measurements were carried out at $298.15 \pm 0.05 \mathrm{~K}$ for four systems in an electrochemical cell such as 
Potassium ISE | electrolyte $\left(m_{S}\right)+$ solute $\left(m_{A}\right)+$ water $\mid$ reference electrode

Nitrate ISE | eiectrolyte $\left(m_{S}\right)+$ solute $\left(m_{A}\right)+$ water $\mid$ reference electrode.

The activity coefficients of the electrolyte measured at various concentrations of amino acid are listed in Table 2.1 to Table 2.4. Table 2.5 lists the pooled standard deviations (Skoog and Leary, 1992), which fall within the range from 0.002 to 0.005 . At least three replicates were measured for each point. The results for $\Delta E^{(\prime)}$ and $\Delta E^{(2)}$ are listed in Tables A-I to A-4 in Appendix A.

For the calculation of the activity coefficients of the amino acids in the electrolyte solutions, the ratio of the activity coefficients of the electrolytes in the solutions with and without amino acids were correlated with the following equation (Khoshkbarchi and Vera, 1996a):

$$
v \ln \frac{\gamma_{ \pm}^{(2)}}{\gamma_{z}^{(1)}}=C_{1} m_{A}+C_{2} m_{S} m_{4}+C_{3} m_{A}^{2}+C_{4} m_{A} m_{S}^{2}+C_{5} m_{A}^{3}+C_{6} m_{S} m_{A}^{2}
$$

The values of the constants and the root mean square deviation obtained in the correlation of results are given in Table 2.6. The root mean square deviation is defined as:

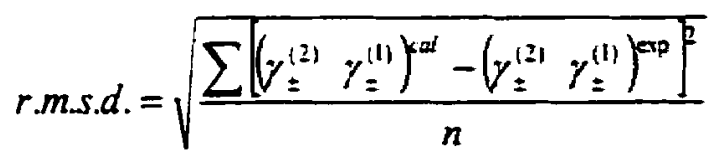

As shown in Table 2.6, the six parameters equation 2.10 gives a very accurate correlation necessary for further calculations.

According to thermodynamics, the activity coefficient of amino acid is related to the mean ionic activity coefficient of the electrolyte via the cross differential relation (Lewis and Randall, 1961): 
Chapter 2. ELECTROCHEMICAL MEASUREMENT OF ACTIVITY COEFFICIENTS OF ALINO ACIDS...

Table 2.1 Experimental results for $\mathrm{NaNO}_{3}+\mathrm{DL}$-serine system

\begin{tabular}{|c|c|c|c|c|c|}
\hline$\overline{\mathrm{m} \mathrm{NaNO}} \Rightarrow$ & 0.1 & 0.3 & 0.5 & 0.7 & 1.0 \\
\hline $\begin{array}{c}\text { m DL-serine } \\
\Downarrow\end{array}$ & & & & & \\
\hline$\overline{0}$ & l & I & 1 & l & 1 \\
\hline 0.05 & 0.9889 & 0.9915 & 0.9935 & 0.9948 & 0.9961 \\
\hline 0.1 & $0.979 \hat{j}$ & 0.9844 & 0.9870 & 0.9889 & 0.9922 \\
\hline 0.15 & 0.9703 & 0.9767 & 0.9806 & 0.9851 & 0.9870 \\
\hline 0.2 & 0.9621 & 0.9697 & 0.9754 & 0.9793 & 0.9831 \\
\hline 0.25 & 0.9540 & 0.9634 & 0.9703 & 0.9742 & 0.9774 \\
\hline 0.3 & 0.9459 & 0.9558 & 0.9628 & 0.9691 & 0.9729 \\
\hline 0.35 & 0.9385 & 0.9496 & 0.9577 & 0.9646 & 0.9691 \\
\hline 0.4 & 0.9312 & 0.9428 & 0.9527 & 0.9584 & 0.9659 \\
\hline
\end{tabular}

Table 2.2 Experimental results for $\mathrm{NaNO}_{3} \div \mathrm{DL}$-valine system

\begin{tabular}{llllll}
\hline $\mathrm{m} \mathrm{KNO} ; \Rightarrow$ & 0.1 & 0.3 & 0.5 & 0.7 & 1.0 \\
\hline $\begin{array}{l}\mathrm{m} \text { DL-valine } \\
\Downarrow\end{array}$ & \multicolumn{5}{c}{$\gamma_{=}^{(2)} / \gamma_{=}^{(1)}$} \\
& & & & & \\
\hline 0 & 1 & 1 & 1 & 1 & 1 \\
0.1 & 0.9973 & 0.9980 & 1.0006 & 1.0027 & 1.0040 \\
0.2 & 0.9921 & 0.9960 & 0.9999 & 1.0053 & 1.0079 \\
0.3 & 0.9868 & 0.9934 & 0.9993 & 1.0033 & 1.0106 \\
0.4 & 0.9816 & 0.9889 & 0.9974 & 1.0040 & 1.0126 \\
0.5 & 0.9751 & 0.9869 & 0.9987 & 1.0040 & 1.0126 \\
\hline
\end{tabular}


Chapter 2. ELECTROCHEMICAL MEASUREMENT OF ACTIVITY COEFFICIENTS OF AMINO ACIDS...

Table 2.3 Experimental results for $\mathrm{KNO}_{3}+\mathrm{DL}$-serine system

\begin{tabular}{lllll}
\hline $\mathrm{m} \mathrm{KNO} 3 \Rightarrow$ & 0.1 & 0.3 & 0.5 & 0.7 \\
\hline $\mathrm{m} \mathrm{DL}$-serine & & $\gamma_{=}^{(2)} / \gamma_{z}^{(1)}$ & & \\
$\Downarrow$ & & & & \\
\hline 0 & 1 & $l$ & 1 & 1 \\
0.01 & 0.9962 & 0.9977 & 0.9992 & 1 \\
0.03 & 0.9940 & 0.9955 & 0.9977 & 1 \\
0.05 & 0.9910 & 0.9932 & 0.9962 & 0.9970 \\
0.1 & 0.9814 & 0.9858 & 0.9925 & 0.9940 \\
0.15 & 0.9703 & 0.9806 & 0.9873 & 0.9917 \\
0.2 & 0.9594 & 0.9747 & 0.9828 & 0.9888 \\
0.25 & 0.9501 & 0.9681 & 0.9784 & 0.9851 \\
0.3 & 0.9415 & 0.9623 & 0.9747 & 0.9836 \\
0.35 & 0.9330 & 0.9558 & 0.9710 & 0.9806 \\
0.4 & 0.9240 & 0.9493 & 0.9681 & 0.9762
\end{tabular}

Table 2.4 Experimental results for $\mathrm{KNO}_{3}+$ glycine system

\begin{tabular}{|c|c|c|c|c|}
\hline $\mathrm{m} \mathrm{KNO}_{3} \Rightarrow$ & 0.1 & 0.3 & 0.5 & 0.7 \\
\hline $\begin{array}{l}\text { m Glycine } \\
\Downarrow\end{array}$ & & $\gamma_{z}^{(2)} / \gamma_{=}^{(1)}$ & & \\
\hline $\overrightarrow{0}$ & 1 & 1 & 1 & 1 \\
\hline 0.1 & 0.9797 & 0.9842 & 0.9887 & 0.9917 \\
\hline 0.3 & 0.9433 & 0.9576 & 0.9657 & 0.9745 \\
\hline 0.7 & 0.8795 & 0.9101 & 0.9325 & 0.9439 \\
\hline 1 & 0.8384 & 0.8795 & 0.9067 & 0.9219 \\
\hline 1.3 & 0.8010 & 0.8513 & 0.8842 & 0.9060 \\
\hline 1.6 & 0.7706 & 0.8270 & 0.8636 & 0.8917 \\
\hline 2 & 0.7346 & 0.7974 & 0.8390 & 0.8682 \\
\hline 2.3 & 0.7098 & 0.7813 & 0.8245 & 0.8545 \\
\hline 2.6 & 0.6897 & 0.7643 & 0.8121 & 0.8422 \\
\hline
\end{tabular}


Chapter 2. ELECTROCHEMICAL MEASUREMENT OF ACTIVTY COEFFICIENTS OF AMINO ACIDS...

Table 2.5 Pooled standard deviation of the measured ratio $\gamma_{ \pm}^{(2)} / \gamma_{=}^{(1)}$ System Number of data points pooled standard deviation
A) $\mathrm{NaNO}_{3}+$ DL-serine $+\mathrm{H}_{2} \mathrm{O}$
120
0.002
B) $\mathrm{NaNO}_{3} \div \mathrm{DL}$-valine $+\mathrm{H}_{2} \mathrm{O}$
75
0.002
C) $\mathrm{KNO}_{3}+\mathrm{DL}$-serine $+\mathrm{H}_{2} \mathrm{O}$
120
0.003
D) $\mathrm{KNO}_{3} \div$ Glycine $+\mathrm{H}_{2} \mathrm{O}$
108
0.005

Table 2.6 Coefficients of eqs. (2-10) and (2-13)

\begin{tabular}{llllllll}
\hline System $^{+}$ & $C_{1}$ & $C_{2}$ & $C_{3}$ & $C_{4}$ & $C_{j}$ & $C_{6}$ & $100 \times$ r.m.s.d
\end{tabular}
$\begin{array}{llllllll}\text { A } & -0.461178 & 0.475671 & 0.186180 & -0.183626 & -0.054472 & -0.194646 & 0.0058\end{array}$
$\begin{array}{llllllll}\text { B } & -0.084055 & 0.278430 & -0.159087 & -0.083077 & -0.162574 & -0.038425 & 0.0776\end{array}$
$\begin{array}{llllllll}\text { C } & -0.490994 & 0.941036 & -0.029429 & -0.550696 & 0.142561 & -0.088478 & 0.0719\end{array}$
$\begin{array}{lllllllll}\text { D } & -0.457793 & 0.622482 & 0.053941 & -0.320274 & -0.002268 & -0.043574 & 0.1518\end{array}$

r.m.s.d = root mean square deviation defined by eq. (2-11).

+ systems A, B, C, D are those listed in Table 2.5 


$$
\left(\frac{\partial \ln \gamma_{A}}{\partial m_{\mathrm{S}}}\right)_{m_{t}, T, P}=v\left(\frac{\partial \ln \gamma_{ \pm}}{\partial m_{A}}\right)_{m_{\mathrm{S}}, T_{,}}
$$

Combining eqs.(2.10) and (2.12), the activity coefficient of amino acid is given by:

$$
\ln \frac{\gamma_{A}^{(2)}}{\gamma_{A}^{(1)}}=C_{1} m_{S}+\frac{1}{2} C_{2} m_{S}^{2}+2 C_{3} m_{A} m_{S}+\frac{1}{3} C_{4} m_{S}^{3}+3 C_{S} m_{A}^{2} m_{S}+C_{6} m_{S}^{2} m_{A}
$$

In fact, eq.(2.10) is a virial expansion and the first term, $C_{1}$, represents the pairwise interaction between amino acid molecules and electrolyte molecules. For all the 4 systems studied here, this term is negative, which means an attractive interaction (Khoshkbarchi and Vera, 1996a). The presence of electrolytes decreases the activity of amino acids. Figure 2.2 to 2.5 illustrate the correlation and calculation results obtained using eqs.(2.10) and (2.13).

Figure 2.2 depicts the effect of $\mathrm{DL}$-serine and $\mathrm{NaNO}_{3}$ concentrations on the ratios of activity coefficients $\gamma_{=}^{(2)} / \gamma_{=}^{(1)}$ and $\gamma_{t}^{(2)} / \gamma_{t}^{(1)}$. As shown in the figure, both $\gamma_{ \pm}^{(2)} / \gamma_{=}^{(1)}$ and $\gamma_{A}^{(2)} / \gamma_{A}^{(1)}$ decrease as the molalities of $\mathrm{NaNO}_{3}$ and DL-serine increase. The presence of the amino acid decreases the mean ionic activity coefficient.

Figure 2.3 depicts the effect of DL-serine and $\mathrm{KNO}_{3}$ concentration on $\gamma_{\neq}^{(2)} / \gamma_{=}^{(1)}$ and $\gamma_{A}^{(2)} / \gamma_{i}^{(1)}$. The behavior of the activity coefficients is similar to the systems illustrated in Fig.2.2. Both $\gamma_{ \pm}^{(2)} / \gamma_{ \pm}^{(1)}$ and $\gamma_{A}^{(2)} / \gamma_{A}^{(1)}$ decrease as the molalities of $\mathrm{NaNO}_{3}$ and DL-serine increase. At high concentration of electrolyte, $\gamma_{ \pm}^{(2)} / \gamma_{ \pm}^{(1)}$ decreases less with the increase in concentration of DL-serine for the case of $\mathrm{KNO}_{3}$ than for the case of $\mathrm{NaNO}_{3}$. In the figures this effect is somewhat obscured by the need to use different scales. 
Chapter 2. ELECTROCHEMICAL MEASUREMENT OF ACTIVITY COEFFICIENTS OF AMINO .ACIDS...
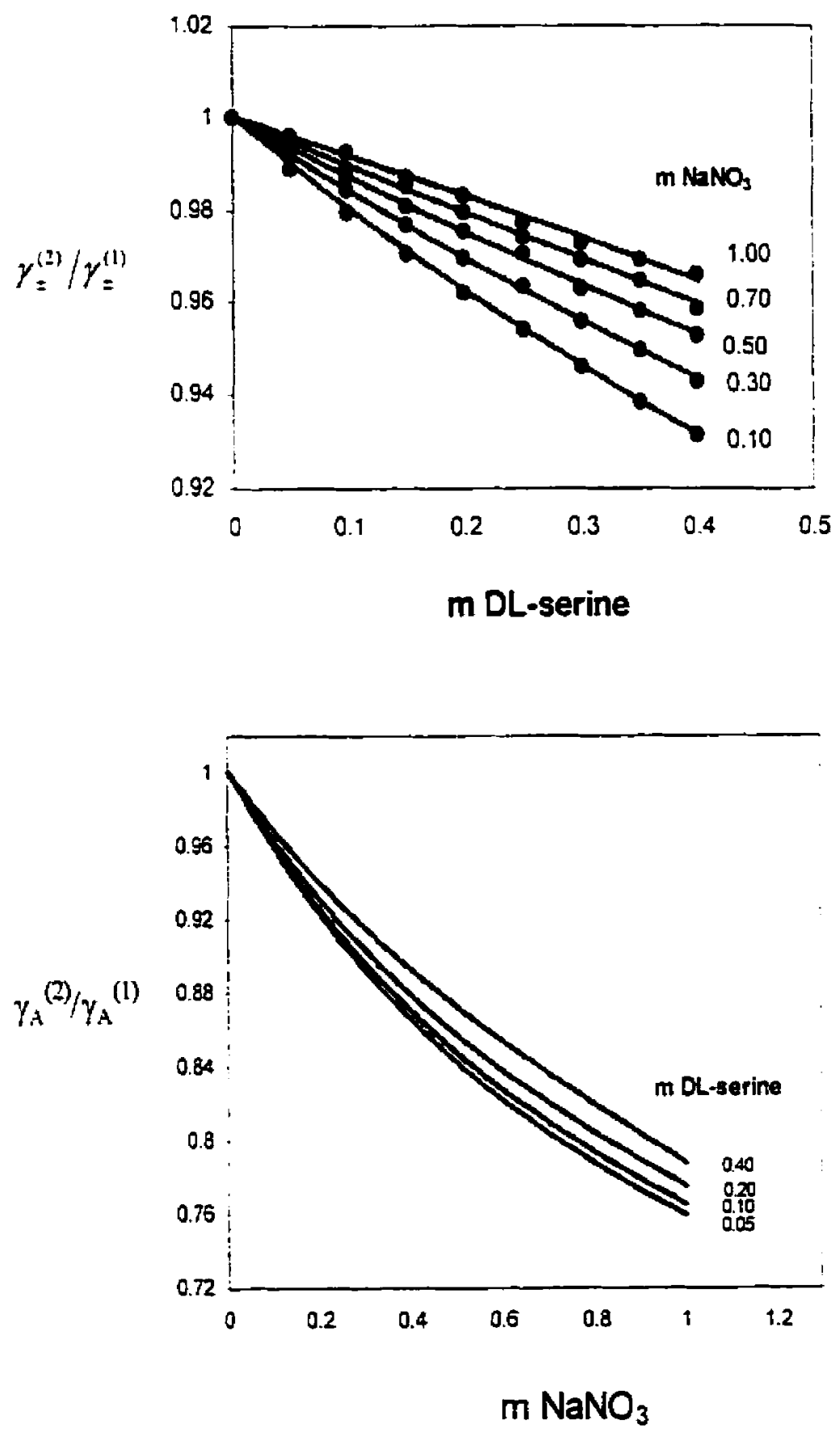

Figure 2.2 Effect of concentrations of $\mathrm{NaNO}_{3}$ and DL-serine, in aqueous solutions at $298.2 \mathrm{~K}$, on the ratios $\gamma_{ \pm}^{(2)} / \gamma_{ \pm}^{(1)} ; \gamma_{A}^{(2)} / \gamma_{A}^{(1)}$. Dots: experimental points; curves: equations (2-10), (2-13), respectively. 
Chapter 2. ELECTROCHEMICAL MEASUREMENT OF ACTIVITY COEFFICIENTS OF AMIINO ACIDS...
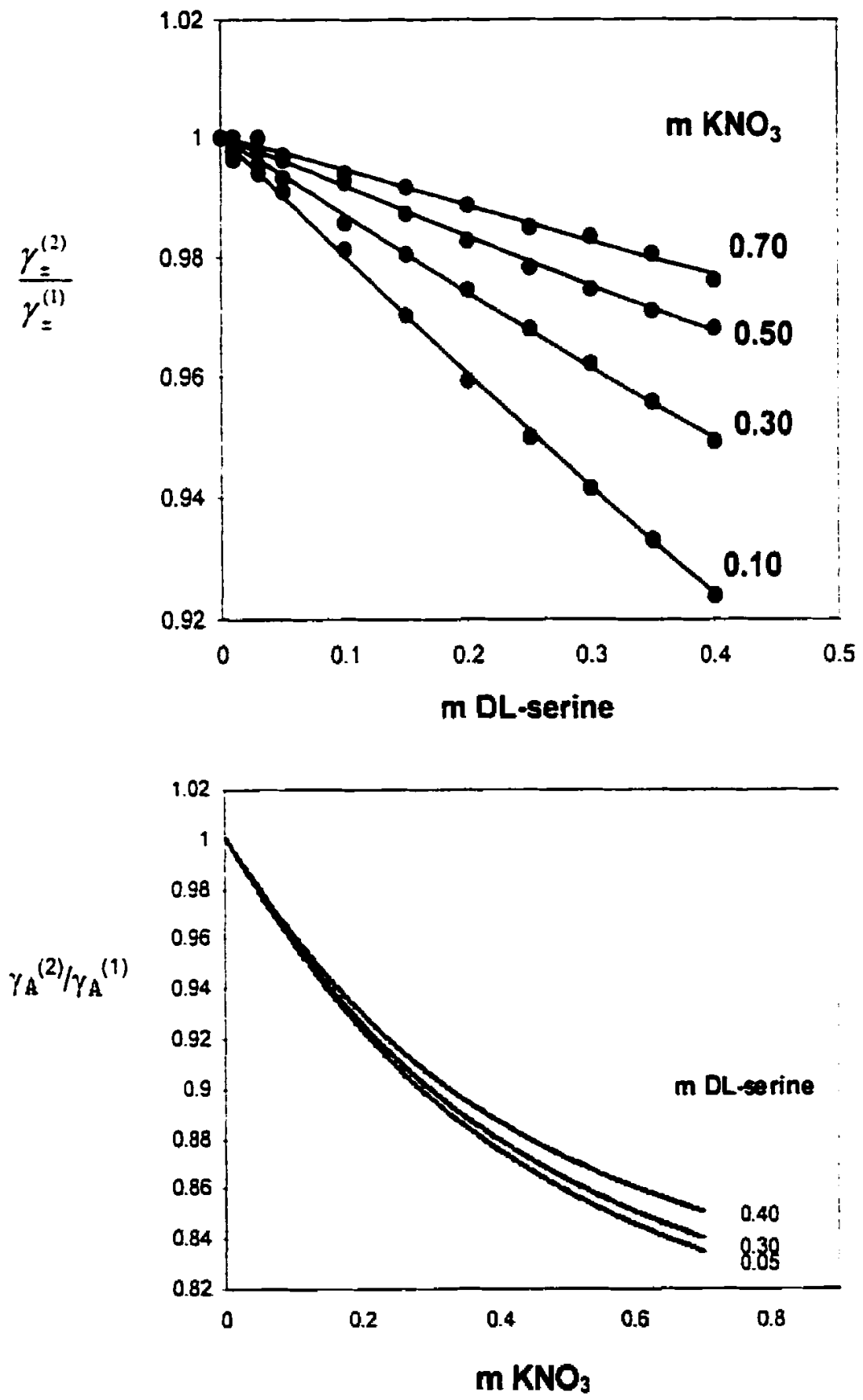

Figure 2.3 Effect of concentrations of $\mathrm{KNO}_{3}$ and $\mathrm{DL}$-serine, in aqueous solutions at $298.2 \mathrm{~K}$, on the ratios $\gamma_{ \pm}^{(2)} / \gamma_{=}^{(1)} ; \gamma_{A}^{(2)} / \gamma_{A}^{(1)}$. Dots: experimental points; curves: equations (2-10), (2-13), respectively. 
In both cases, the effect of the amino acid decreases as concentration of the electrolyte increases. The similarity of these two systems is natural since the only difference between them is the anion $\mathrm{K}^{+} / \mathrm{Na}^{+}$. This effect suggests that higher electrolyte concentrations screen more the electrostatic ion-dipole interactions between DL-serine and the ions, and also increase the importance of the short range interactions, resulting in a smaller effect of a change of DL-serine concentration on the mean ionic activity coefficient. Similarly there is a smaller effect of changes in electrolyte concentration on the activity coefficient of the amino acid.

Figure 2.4 depicts the effect of $\mathrm{DL}$-valine and $\mathrm{NaNO}_{3}$ concentrations on the ratio of activity coefficients, $\gamma_{=}^{(2)} / \gamma_{=}^{(1)}$ and $\gamma_{t}^{(2)} / \gamma_{t}^{(1)}$. At high concentration of $\mathrm{NaNO}_{3}(1.0 \mathrm{~m})$, $r_{=}^{(2)} / \gamma_{=}^{(1)}$ increases as the molality of DL-valine increases, while at concentration of $\mathrm{NaNO}_{3}$ around $0.7, \gamma_{=}^{(2)} / \gamma_{ \pm}^{(1)}$ decreases as the molality of DL-valine increases. For the activity coefficients of the amino acid (DL-valine), a minimum value (against the concentration of $\mathrm{NaNO}_{3}$ ) occurs at each particular concentration of amino acid. When the concentrations of DL-valine are below $0.5, \gamma_{A}^{(2)} / \gamma_{t}^{(1)}$ decreases as the concentration of electrolyte increases, while at $0.5 \mathrm{~m}$ the values of $\gamma_{d}^{(2)} / \gamma_{A}^{(1)}$ become less than those at 0.3 m. A similar behavior was observed for the $\mathrm{DL}$-alanine $+\mathrm{KCl}+\mathrm{H}_{2} \mathrm{O}$ system (SotoCampos et al. 1997).

In fact the overlap of lines is due to the presentation of three dimensional data in a two-dimensional plot. Additional information is gained by re-plotting the values of $\gamma_{A}^{(2)} / \gamma_{A}^{(1)}$ as a function of $m_{A}$ for fixed values of $m_{S}$. Such a plot is presented in Figure 2.5. In this case, the variation of the trace activity coefficient of the amino acid in salt solutions is explicitly shown as a function of salt molality.

The difference between the effect in DL-serine $+\mathrm{NaNO}_{3}$ system and that in DLvaline $+\mathrm{NaNO}_{3}$ system may be a result of the difference of the molecular structures of these two amino acids. In DL-serine there is a -OH group in its hydrocarbon backbone. The presence of this - $\mathrm{OH}$ group decreases the hydrophobic interactions between the 
Chapter 2. ELECTROCHEMICAL MEASUREMENT OF ACTIVITY COEFFICIENTS OF AMINO ACIDS...
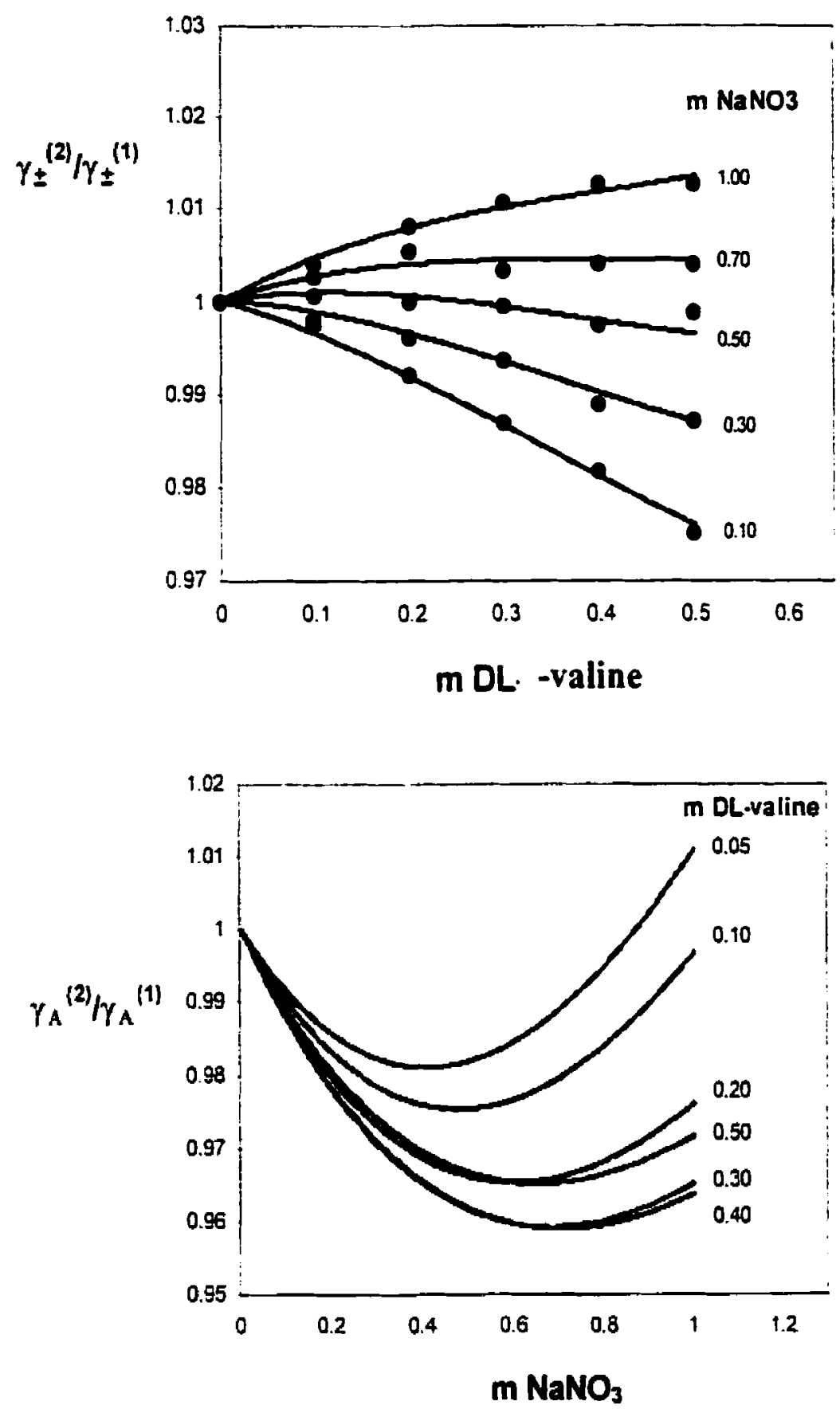

Figure 2.4 Effect of concentrations of $\mathrm{NaNO}_{3}$ and DL-valine, in aqueous solutions at $298.2 \mathrm{~K}$, on the ratios $\gamma_{ \pm}^{(2)} / \gamma_{=}^{(1)} ; \gamma_{A}^{(2)} / \gamma_{A}^{(1)}$. Dots: experimental points; curves: equations (2-10), (2-13), respectively. 
hydrocarbon backbone of DL-serine and the molecules of water. Besides, at high concentrations of $\mathrm{DL}$-valine and $\mathrm{NaNO}_{3}$, probably as a result of the formation of the ionpair complexes, the electrostatic interactions decrease, leading to an increase in the activity coefficient of DL-valine with an increase of $\mathrm{NaNO}_{3}$ molality.

Figure 2.6 depicts the effect of glycine and $\mathrm{KNO}_{3}$ concentrations on $\gamma_{=}^{(2)} / \gamma_{z}^{(1)}$ and $\gamma_{t}^{(2)} / \gamma_{t}^{(1)}$. The behavior of activity coefficients for this system is similar to DL-serine $\div \mathrm{NaNO}_{3} \div \mathrm{H}_{2} \mathrm{O}$ as discussed above. But the activity coefficient decreases more in the former system than in the latter. This difference may be due to the difference of the structure of DL-serine and glycine: DL-serine has a $-\mathrm{OH}$ group in its hydrocarbon backbone and has one $-\mathrm{CH}_{2}$ group more than glycine. The formation of ion-pair complexes in the glycine system and the effect of $-\mathrm{OH}$ may both contribute to the difference.

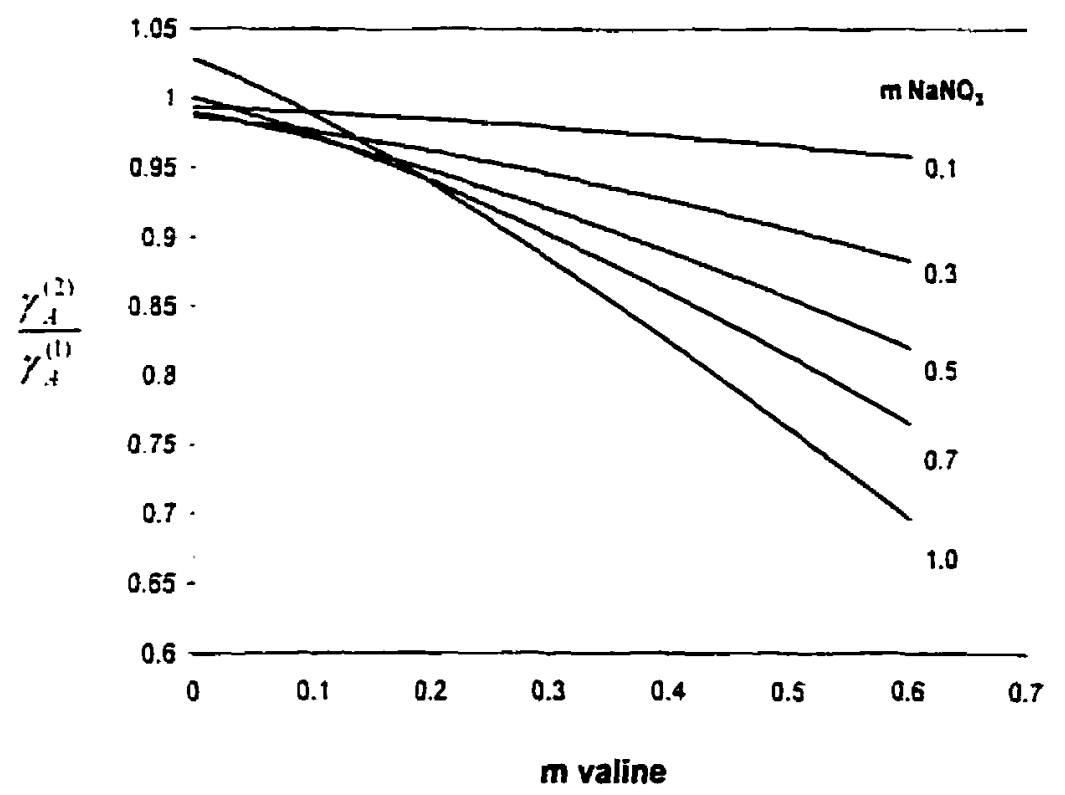

Figure 2.5 Re-plot of $\gamma_{A}^{(2)} / \gamma_{A}^{(1)}$ as a function of $m_{A}$ for fixed values of $m_{S}$ 
Chapter 2. ELECTROCHEMTCAL MEASUREMENT OF ACTIVITY COEFFICIENTS OF AMINO ACIDS...
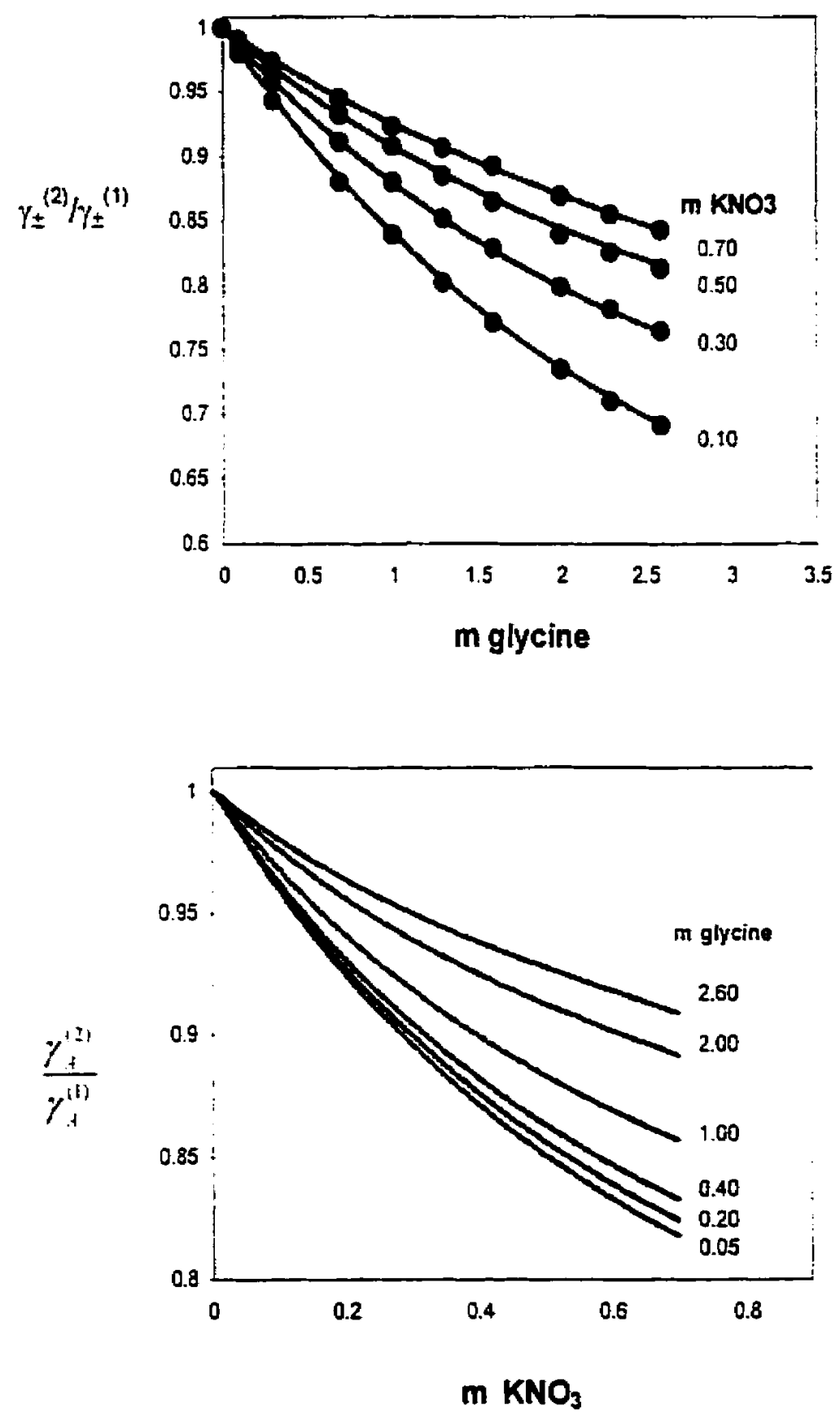

Figure 2.6 Effect of concentrations of $\mathrm{KNO}_{3}$ and glycine, in aqueous solutions at $298.2 \mathrm{~K}$, on the ratios $\gamma_{\equiv}^{(3)} / \gamma_{ \pm}^{(1)} ; \gamma_{A}^{(2)} / \gamma_{A}^{(1)}$. Dots: experimental points; curves: equations (2-10), (2-13), respectively. 


\section{CHAPTER 3: MEASUREMENT OF ACTIVITY COEFFICIENTS USING THE ISOPIESTIC METHOD}

\subsection{Motivation}

For the activity coefficients in $\mathrm{KNO}_{3}+\mathrm{DL}$-serine $+\mathrm{H}_{2} \mathrm{O}$ system, the results obtained in this work are different from previous measurements obtained by a Summer Student using the EC method (Silverberg, 1998). The activity coefficients of DL-serine obtained by Silverberg were greater than 1.0 when $\mathrm{KNO}_{\text {氵 }}$ molality was greater than 0.3 .

In the calibration of the slope (S) for eq.(2-9) using eq.(2-7) and data or the system $\mathrm{KNO}_{3}$ +water, it was found that the response of the pair of electrodes was slightly nonlinear. This is possibly due to interferences when both potassium ISE and nitrate ISE are used in the measurement. The details of this phenomenon and a theoretical explanation can found in literanre (Haghtalab, 1990 and references cited in that work). Some ertor could be introduced by this interference in the measurement recorded by both electrodes.

With the above motivation, the purpose of this part of work was to use the isopiestic method to measure the activity coefficients for this system and compare the results with those obtained from the EC method.

\subsection{Theoretical Background}

When a ternary system, amino acid $\left(m_{A}\right) \div$ electrolyte $\left(m_{S}\right)+$ water, is in equilibrium with a reference system (electrolyte + water), then the activities of water in the two systems are equal:

$$
a_{I V}=a_{W V}^{\mathrm{Ref}}
$$

According to the definition of osmotic coefficient $\phi_{S}$ for the electrolyte solution: 


$$
55.51 \ln a_{w}=-v m_{s} \phi_{S}
$$

eq. $(3-1)$ can be written as:

$$
m_{s} \phi_{S}=m_{s}^{\text {Ref }} \phi_{s}^{\text {Ref }}
$$

If the osmotic coefficient of the reference solution is known as a function of molality of the electrolyte $\left(m_{s}\right)$, then eq.(3-3) can be used to calculate the unknown $\phi_{s}$. For a solution containing one solute (say electrolyte), the mean ionic activity coefficient can be calculated with the following equation:

$$
\ln \gamma=\left(\phi_{s}-1\right)+\int_{0}^{m_{s}}\left(\phi_{s}-1\right) d \ln m_{s}
$$

For a solute $A$ in a ternary system, the cross differential relation should be used (Bower and Robinson, 1965):

$$
\left(\frac{\partial \ln \gamma_{A}}{\partial m_{S}}\right)_{m m_{1}}=v\left(\frac{\partial \ln \gamma_{s}}{\partial m_{A}}\right)_{m_{s}}=\frac{\Delta}{m_{f} m_{s}}
$$

where $\Delta$ is defined as:

$$
\Delta=m_{S} \phi_{S}-v m_{S} \phi_{S}^{0}-m_{A} \phi_{A}^{0}
$$

where $\phi_{S}^{0}$ represents the osmotic coefficient of the binary solution (electrolyte + water) at molality $m_{s}$, which is not equal to $\phi_{S}^{R}$ (at molality $m_{s}^{R}$ ), and $\phi_{A}^{0}$, the osmotic coefficient of the binary solution (amino acid + water) at molality $m_{A}$.

At each set of molalities, $\left(m_{s}, m_{d}\right), \Delta$ is evaluated, and a polynomial functional dependence is assumed: 


$$
\frac{\Delta}{m_{A} m_{S}}=C_{0}+C_{1} m_{A}+C_{2} m_{S}+C_{3} m_{A}^{2}+C_{3} m_{S}^{2}+C_{5} m_{A} m_{S}
$$

The coefficients of eq.(3-7) are obtained by fitting the experimental data with the equation. Then the activity coefficients are calculated with the following equations (Bower and Robinson, 1965):

$$
\begin{aligned}
& \ln \frac{\gamma_{A}^{(2)}}{\gamma_{A}^{(1)}}=m_{S}\left(C_{0}+C_{1} m_{A}+\frac{1}{2} C_{2} m_{S}+C_{3} m_{A}^{2}+\frac{1}{3} C_{4} m_{S}^{2}+\frac{2}{3} C_{5} m_{A} m_{S}\right) \\
& v \ln \frac{y_{=}^{(2)}}{\gamma_{=}^{(1)}}=m_{A}\left(C_{0}+\frac{1}{2} C_{1} m_{A}+C_{2} m_{S}+\frac{1}{3} C_{3} m_{A}^{2}+C_{t} m_{S}^{2}+\frac{2}{3} C_{S} m_{A} m_{S}\right)
\end{aligned}
$$

\subsection{Experimental Set Up and Measurements}

Several versions of set up were built and tested before the final one was accepted.

The first set up used was constructed as follows: four de-connectable flasks with volume $100 \mathrm{ml}$ each were connected (ground glass connection) with a straight glass tube closed by a vacuum vaive. It took too a very long time to reach the equilibrium.

The second version of the set up was different from the first one: four flasks, of $100 \mathrm{ml}$ volume, were connected to a spherical chamber to avoid the diffusion through the tube. Still it was too difficult to reach equilibrium and it was decided to shorten the connecting necks of the flasks and decrease their volume.

In the third version of the set up four cells with volume of around $10 \mathrm{ml}$ each were connected permanently with a spherical chamber. This set up worked much better than previous versions. Unfortunately it was difficult to fill the solutions through the upper opening of the chamber.

Finally the fourth and last version was constructed: four cells with $10 \mathrm{ml}$ volume were connected with a semi-spherical chamber using screw connections 


\section{Chapter 3. MEASUREMENT OF ACTIVITY COEFFICIENT USING THE ISOPIESTIC METHOD}

(CG-350, CHEMGLASS), as illustrated in Figure 3.1. While the three previous setups were thermostabilized in a water bath, the fourth setup was put in a custommade air bath which kept the temperature at $298.15 \pm 0.05 \mathrm{~K}$. The solutions were distributed in the four cells as follows: two cells contained binary solution $\left(\mathrm{KNO}_{3}+\right.$ $\mathrm{H}_{2} \mathrm{O}$ ), and two cells contained the ternary solution (DL-serine $+\mathrm{KNO}_{3}+\mathrm{H}_{2} \mathrm{O}$ ). The concentrations of the solutions were measured using the Atomic Absorption (AA) (Thermo Jarrell Ash, Smith-Hieftije (1) method. Generally, around 4 weeks were needed for the system to reach equilibrium.

\section{Operation procedure}

(1) Two reference solutions $\left(\mathrm{KNO}_{3}+\right.$ water) with the different concentrations of the electrolyte were filled in two cells. The other two cells were filled with solutions of the unknown system $\left(\mathrm{KNO}_{3}+\mathrm{DL}\right.$-serine - water) with the same salt and amino acid concentration ratio, but different amount of water.

(2) The chamber was evacuated and the air bath was set at $298.15 \mathrm{~K}$.

(3) The concentrations in each cell were measured periodically. When the concentrations of the two reference systems were found to be equal and the concentrations of the two unknown systems were also equal, the system was considered to be in equilibrium. 
Chapter 3. MEASUREMENT OF ACTIVTTY COEFFICIENT USIVG THE ISOPIESTIC METHOD

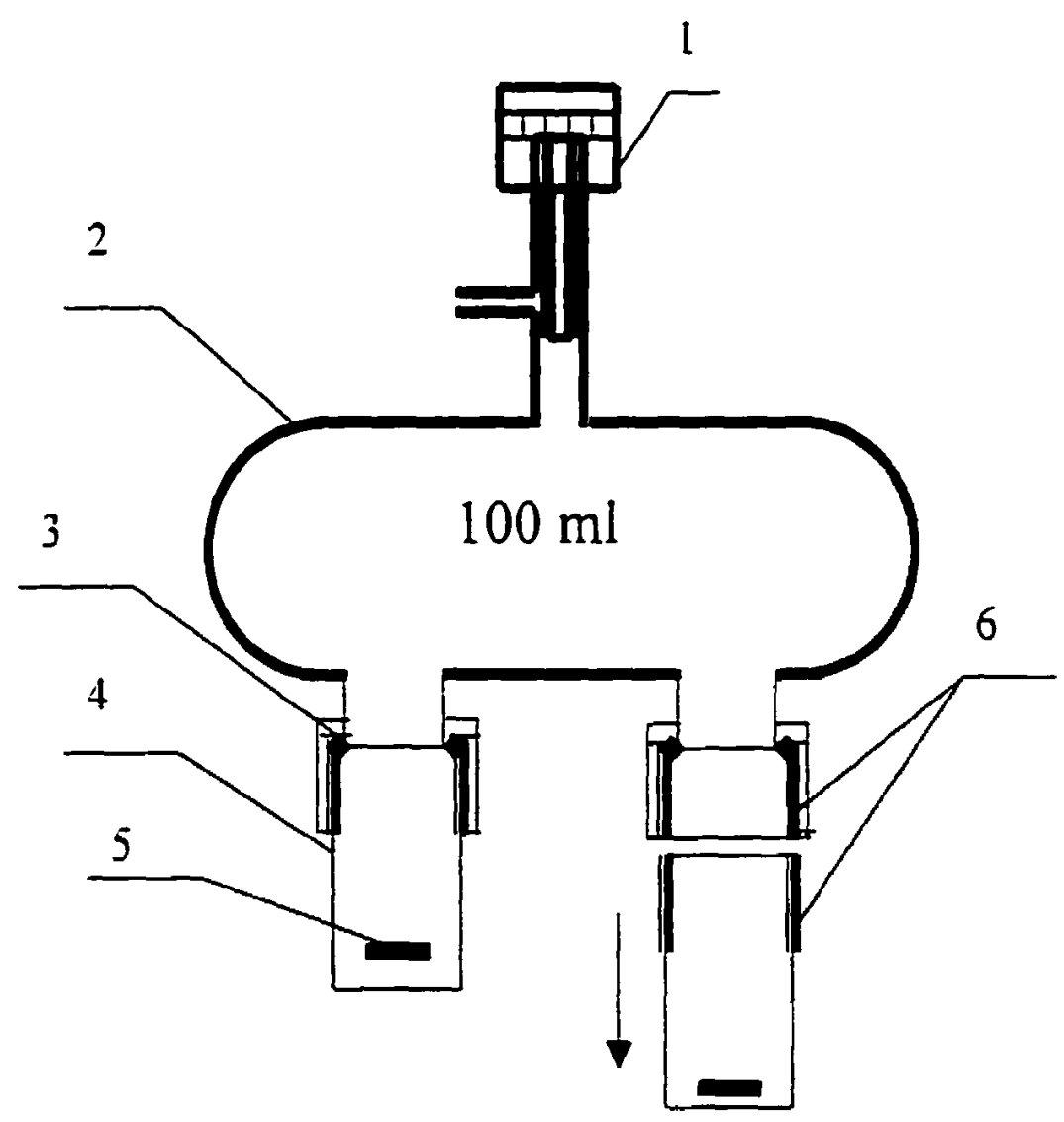

1: vacuum stopcock; 2: vapor chamber; 3 : sealing washer; 4 : cell (total $4 \times 10$ ml); 5: magnet; 6: chem-thread (CG-350, CHEMGLASS)

Figure 3.1 View of isopiestic set up 


\subsection{Results and Discussions}

The values for osmotic coefficients in the binary system $\left(\mathrm{KNO}_{3}+\right.$ water; $\mathrm{DL}-$ serine + water) at various solute concentrations were obtained as follows. First the activity coefficients of amino acid and electrolyte in aqueous solutions at $298.15 \mathrm{~K}$ were obtained from literature (Fasman, 1976; Zaytsev and Aseyev, 1992), respectively. For the mean ionic activity coefficient of the electrolyte, the extended Debye-Huckel equation for l:l electrolyte is given by (Butler, 1998):

$$
\ln \gamma_{2}=-\frac{A \sqrt{m}}{1+B_{1} \sqrt{m}}+B_{2} m+B_{3} m^{2}+\cdots
$$

Theoretical value $A$ is 1.174 at $298.15 \mathrm{~K}$ (Butler, 1998). In the Davies model (Davies. 1962)., only the first two terms are used with $B_{l}=1$ and $B_{2}=-0.2$. In this case the correlation error was considered high with $A A D$ (average absolute deviation) $1.23 \%$. For a benter correlation, three tems were used. and treated both $B_{l}$ and $B_{3}$ were treated as adjustable parameters. The values of the parameters and the correlation results are listed in Table 3.1 .

For the asymmetrically normalized activity coefficient of the amino acid. we used the following polynomial function:

$$
\ln \gamma_{A}=b m_{A}+c m_{A}^{2}+d m_{s}^{3}
$$

The values of the parameters and the correlation results are listed in Table 3.2.

Table 3.1 Correlation results by eq. $(3-10)$

\begin{tabular}{lllll}
\hline System & $B_{I}$ & $B_{2}$ & $B_{3}$ & $\mathrm{AAD} \%$ \\
\hline $\mathrm{KNO}_{3}+$ water & 0.8927 & -0.2 & 0.009807 & 0.55 \\
\hline
\end{tabular}


Table 3.2 Correlation results by eq. $(3-11)$

\begin{tabular}{lllll}
\hline System & $b$ & $c$ & $d$ & AAD\% \\
\hline DL-serine + water & -0.263674 & 0.052884 & -0.004677 & 0.12
\end{tabular}

The osmotic coefficient is given by (Robinson and Stokes, 1959):

$$
\phi=1 \div \frac{1}{m} \int_{0}^{m} m d \ln \gamma
$$

For electrolyte in water. from eqs. $(3-10)$ and $(3-12)$, we have

$$
\phi=1-\frac{A \sqrt{m}}{\left(B_{1} \sqrt{m}\right)^{3}}\left[1+B_{1} \sqrt{m}-2 \ln \left(1+B_{1} \sqrt{m}\right)-\frac{1}{1+B_{1} \sqrt{m}}\right]+\frac{1}{2} B_{2} m+\frac{2}{3} B_{3} m^{2}
$$

and for DL-serine in water. from eqs.(3-11) and (3-12):

$$
\phi=1+\frac{1}{2} b m_{A}+\frac{2}{3} c m_{-1}^{2}+\frac{3}{4} d m_{A}^{3}
$$

Eqs.(3-13) and (3-14) were used to calculate the osmotic coefficients in eq.(3-6) for the two aqueous systems at various concentrations of solutes, respectively.

Finally, after obtaining the coefficients by fitting eq.(3-7), eqs.(3-8) and (3-9) can be used to calculate the activity coefficients for the ternary systems. The measured data are listed in Table 3.2, and the regressed values for the coefficient $\left(C_{0}\right.$ to $C_{5}$ ) are given in Table 3.3 . 
Chapter 3. MEASUREMENT OF ACTIVTTY COEFFICIENT USING THE ISOPIESTIC METHOD

\subsection{Comparison with the Electrochemical Method}

Figure 3.2 depicts a comparison of the mean ionic activity coefficients obtained by the EC method and isopiestic method at the salt molality of 0.3 . Figure 3.3 depicts the activity coefficients of DL-serine in the ternary system measured by two methods at amino acid molality of 0.3.Both methods give comparable trends in the sense that the activity coefficients are less than 1.0 , though some differences are observed.

The deviation of the results of the IP method from those of the EC method comes from two major sources: (1) the time was still not long enough to reach the equilibrium: (2) errors from the concentration analysis. Since for the systems considered the activity coefficients do not differ significantly from 1.0 any small deviation can not be ignored for an accurate measurement.

In addition, the concentration range for both the salt and the amino acid were not wide enough: at around 0.3 in molality of the amino acid. the extrapolation of the results to lower and higher concentrations should be taken with care. In order to obtain better results over wide concentration range, more experiments would be necessary.

Time constraints of the program forced us to stop these measurements. In any case, the main objective of this section was attained since the trend of change was confirmed. 
Chapter 3. MEASUREMENT OF ACTIVITY COEFFICIENT USING THE ISOPIESTIC METHOD

Table 3.2 Measured data from isopiestic method

\begin{tabular}{lllllll}
\hline$m_{A}$ & $m_{S}$ & $m^{\text {ReI }}$ & $\phi_{A}^{0}$ & $\phi_{s}^{0}$ & $\phi^{\text {hed }}$ & $\Delta / m_{A} m_{S}$ \\
\hline 0.2889 & 0.2777 & 0.4389 & 0.9710 & 0.8584 & 0.8303 & -0.3545 \\
0.2123 & 0.3323 & 0.4517 & 0.9787 & 0.8480 & 0.8283 & -0.3270 \\
0.1882 & 0.4312 & 0.5376 & 0.9812 & 0.8315 & 0.8158 & -0.3031 \\
0.2008 & 0.4213 & 0.5345 & 0.9799 & 0.8330 & 0.8163 & -0.3076 \\
0.2203 & 0.2923 & 0.4156 & 0.9779 & 0.8555 & 0.8340 & -0.3469 \\
0.2755 & 0.2846 & 0.4384 & 0.9724 & 0.8570 & 0.8304 & -0.3521 \\
0.2140 & 0.2170 & 0.3366 & 0.9785 & 0.8714 & 0.8472 & -0.3715 \\
0.2086 & 0.2156 & 0.3323 & 0.9791 & 0.8717 & 0.8480 & -0.3677 \\
0.2999 & 0.2245 & 0.3911 & 0.9700 & 0.8697 & 0.8379 & -0.3861 \\
0.3288 & 0.2010 & 0.3834 & 0.9671 & 0.8752 & 0.8392 & -0.3982 \\
0.2407 & 0.2614 & 0.3956 & 0.9759 & 0.8617 & 0.8372 & -0.3656 \\
0.2632 & 0.2655 & 0.4122 & 0.9736 & 0.8608 & 0.8345 & -0.3631 \\
0.3455 & 0.2345 & 0.4259 & 0.9654 & 0.8674 & 0.8323 & -0.3876 \\
0.1340 & 0.3870 & 0.4635 & 0.9866 & 0.8386 & 0.8265 & -0.2915 \\
\hline
\end{tabular}

Table 3.3 Correlation results

\begin{tabular}{lllllll}
\hline $\mathrm{C}_{0}$ & $\mathrm{C}_{1}$ & $\mathrm{C}_{2}$ & $\mathrm{C}_{3}$ & $\mathrm{C}_{4}$ & $\mathrm{C}_{5}$ & r.m.s.d \\
\hline-0.34559 & -1.02022 & 0.62344 & 1.24695 & -0.74989 & 0.75688 & 0.00327 \\
\hline
\end{tabular}


Chapter 3 MEASUREMENT OF ACTIVITY COEFFICIENT USING THE ISOPIESTIC METHOD

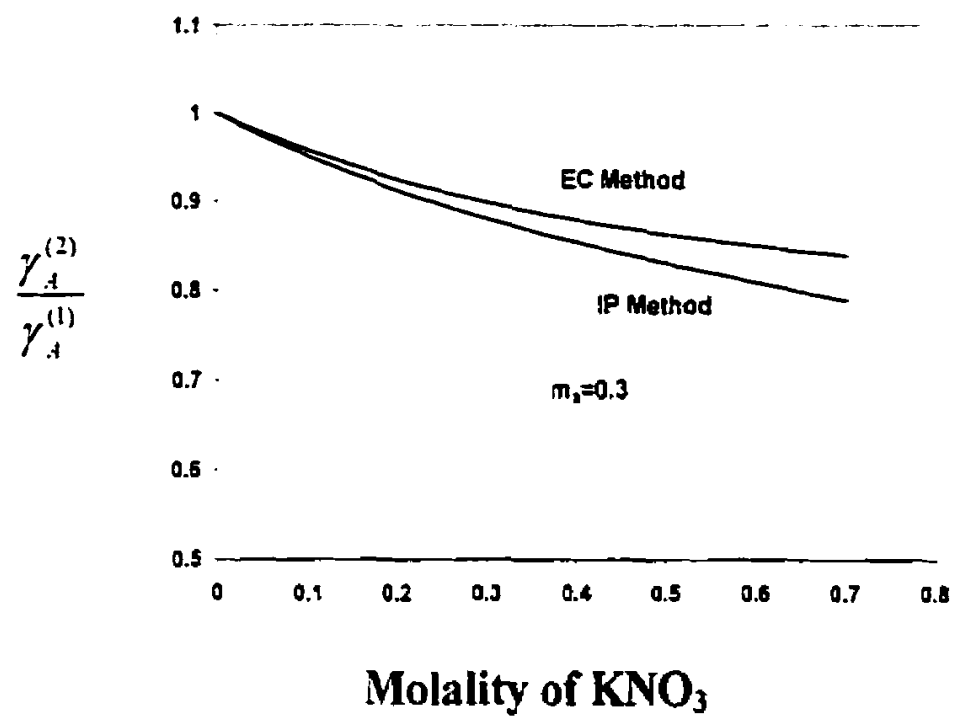

Figure 3.2 Comparison of activity coefficients of

DL-serine by two methods

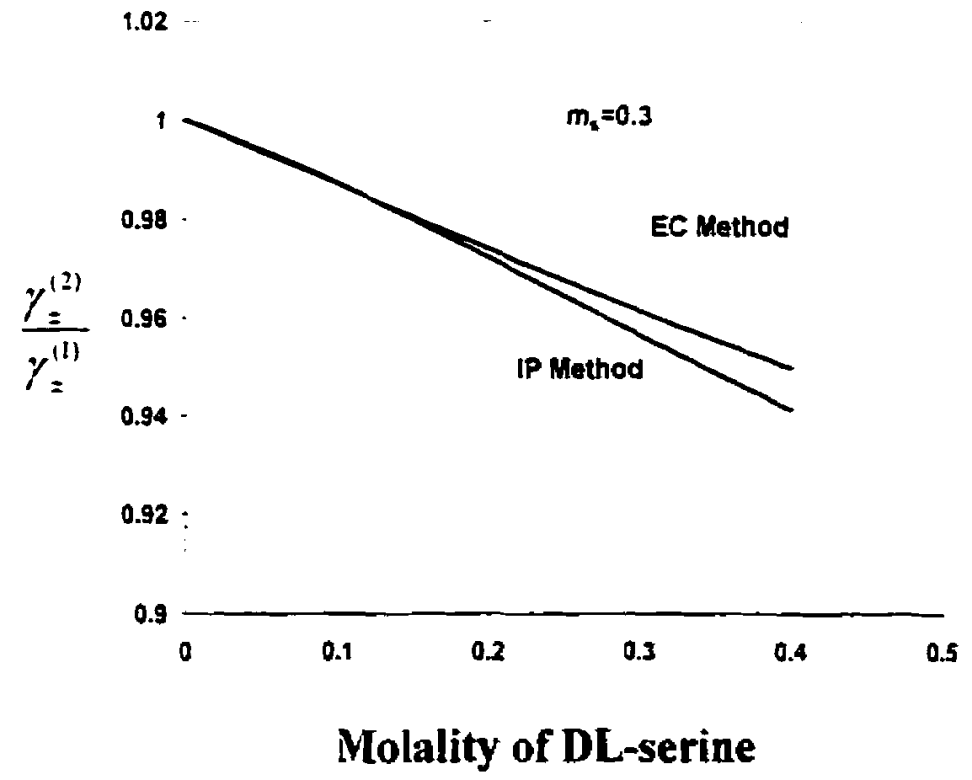

Figure 3.3 Comparison of mean ionic activity coefficient by two methods 

METHOD

The advantages and disadvantages of the two methods are listed below:

\begin{tabular}{lll} 
& Advantages & Disadvantages \\
\hline Electrochemical & $\begin{array}{l}\text { Accurate at low } \\
\text { concentrations, } \\
\text { less expensive, } \\
\text { fast }\end{array}$ & $\begin{array}{l}\text { System and concentration } \\
\text { are limited by electrode }\end{array}$ \\
\hline Isopiestic & $\begin{array}{ll}\text { Useful for medium } \\
\text { and high concentrations }\end{array}$ & $\begin{array}{l}\text { Slow to reach to } \\
\text { equilibrium } \\
\text { Inaccurate at low } \\
\text { concentrations }\end{array}$ \\
\hline
\end{tabular}




\section{CHAPTER 4: MODELING}

In this chapter we discuss two models. The first, presented in section 4.1 , is a direct application of the model proposed previously by Kohshibarchi and Vera (1996a). The second, presented in section 4.2 , is a modification of a more complex model proposed by Khoshkbarchi and Vera (1996c).

\subsection{Gibbs Free Energy Model with the NRTL Equation}

For the modeling of aqueous solutions containing electrolytes and nonelectrolytes, the equation for the excess Gibbs free energy is normally written as:

$$
G^{E}=G_{L R}^{E}+G_{S R}^{E}
$$

where the superscripts 'LR'. 'SR' refer to long and short range interactions, respectively.

A model was proposed by Kohshibarchi and Vera (1996a) in which either the Wilson or the NRTL equations were used to represent the short range contributions. In this model, the activity coefficient of an electrolyte in an electrolyte + amino acid + water system is given by:

$$
\ln \gamma_{=}^{(m)}=\ln \gamma_{=}^{(m), L R}+\frac{1}{v}\left\{\ln \gamma_{S}^{(s), S R}-\lim _{s_{A} \rightarrow 0}\left(\ln \gamma_{S}^{(x), S R}\right)+\ln \left(\frac{1+0.001 M_{W} m_{S}}{1+0.001 M_{W}\left(m_{S}+m_{A}\right)}\right)\right\}
$$

where the subscripts 'S', ' $\mathrm{A}$ ' and 'W' refer to electrolyte, amino acid, and water; the superscripts $(\mathrm{m})$ and $(\mathrm{x})$ refer to molality and molar fraction based activity coefficient, respectively; $L_{w}$ is the molecular weight of water, $m_{s}$ and $m_{f}$ refer to the molalities of electrolyte and amino acid in the solution. Clearly, at zero amino acid concentration, the mean ionic activity coefficient of the electrolyte reduces to the long range (LR) contribution. The last term of eq.(4-2) arises from the conversion of the molality based activity coefficient into the molar fraction based one. In the case of the binary system electrolyte + water, the following equation holds: 


$$
\gamma_{ \pm}^{(x)}=\gamma_{ \pm}^{(m)}\left(1+0.001 M_{w} m_{s}\right)
$$

When values of the mean ionic activity coefficient are needed. a model for the long range interaction term, namely activity coefficient of electrolyte in water, is required. There are many different models for this purpose, such as Bromley model (Bromley, 1973), K.V model (Kohsinkbarchi and Vera, 1996b). In this work, we only need the ratio of the activity coefficients of the electrolyte in a aqueous solution in the presence and absence of the amino acid, then eq.(4-2) is written as:

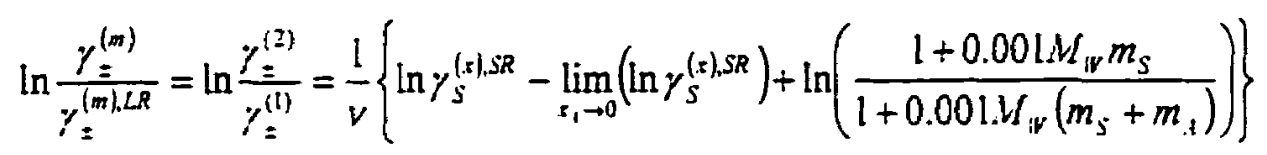

where $Y_{=}^{(m), i n}$ is the mean ionic activity coefficient of the electrolyte in the binary aqueous solution at the same electrolyte molality as in the ternary systems, which is identical to $y_{:}^{(3)}$. Similarly, the ratios of the activity coefficients of amino acid in a aqueous solution with and without electrolyte is given by:

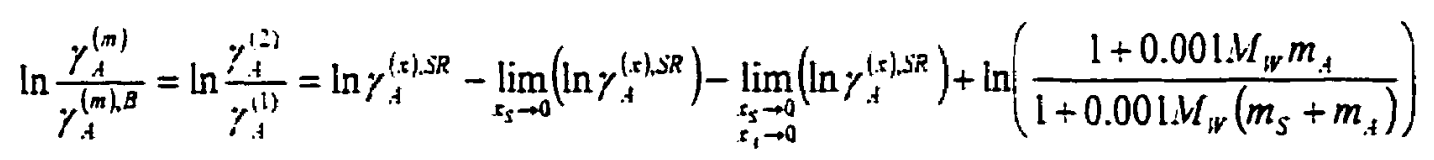

where superscript $B$ refers to binary system. The third term in the right hand side of eq.(4-5) is introduced to meet the limit at infinite dilution (Kohshkbarchi and Vera 1996a).

As it can be seen from eq.(4-4) and (4-5), for the purposes of this work, a model for the short range interaction activity coefficient suffices to give a complete formulation. Here the NRTL equation is used: 


$$
\ln \gamma_{i}=\frac{\sum_{j=1}^{3} x_{j} \tau_{j t} G_{j t}}{\sum_{j=1}^{3} x_{j} G_{j t}}+\sum_{j=1}^{3} \frac{x_{j} G_{l j}}{\sum_{k=1}^{3} x_{k} G_{k j}}\left(\tau_{l y}-\frac{\sum_{k=1}^{3} x_{k} \tau_{k j} G_{k j}}{\sum_{k=1}^{3} x_{k} G_{k j}}\right)
$$

with

$$
G_{u \prime}=\exp \left(-\alpha \tau_{y}\right) \quad(\mathrm{i}, \mathrm{j}=1,2,3)
$$

where $\tau_{\mu}$ 's are the binary parameters, with $\tau_{u}=0$. Here we use the convention: $1=S$ (electrolyte). $2=A$ (amino acid), $3=W$ (water). The binary parameters for the amino acid + water system $\left(\tau_{A, W}, \tau_{W,-t}\right)$ were estimated using literanure data (Fasman, 1976). $\tau_{S, A}$ and $\tau_{S, W}$ were estimated from ternary experimental data with the assumptions $\tau_{A, S}=\tau_{S, A}$ and $\tau_{W, S}=\tau_{S, W}$. The parameter $\alpha$ was set constant at 0.3 .

Following Kohshkbarchi and Vera (1996a) for the calculation of the short range contribution. the electrolyte was considered to be a molecular component and its molar fraction in a ternary system is calculated by:

$$
x_{s}=\frac{n_{s}}{n_{d}+n_{s}+n_{w}}
$$

\subsection{A New Model Based on a Simplified Perturbation Theory}

\subsubsection{Theoretical Background}

Khoshkbarchi and Vera (1996c) proposed a theoretical model based on the perturbation theory. For the chemical potential, using the primitive approximation, this theory gives

$$
\mu_{t}=\mu_{t}^{\text {Ref }}+\mu_{t}^{\text {Per }}
$$


where superscripts 'Ref' and 'Per' refer to the reference and perturbation contributions to the chemical potential, respectively. Using the hard sphere expression as reference model and model potentials for perturbation, the activity coefficient is expressed as

$$
\ln \gamma_{\imath}=\frac{8 \eta+9 \eta^{2}+3 \eta^{3}}{(1-\eta)^{3}}-\frac{4 \pi \rho}{k T}\left\{\frac{8}{9} \varepsilon \sigma^{3}+\frac{D^{4}}{9\left(4 \pi \varepsilon_{0} \varepsilon_{r}\right)^{2} k T \sigma^{3}}\right\}
$$

where $\sigma$ and $\varepsilon$ are the molecular diameter and the depth of the molecular potential well according to the Lennard-Jones (LJ) potential model, respectively, $\varepsilon_{0}$ the permitivity of vacuum. $\varepsilon_{r}$, the relative dielectric constant of the medium (water), $D$ is the dipole moment of the amino acid, $\rho=N_{1} / V$, the number density of the component $(i)$ in the solution with total volume $V, k$ is the Boltzmann constant. $T$ is the absolute temperature. and tinally, $\eta$ is given by:

$$
\eta=\frac{1}{6} \pi \rho \sigma^{3}
$$

The first term in the right hand side of eq.(4-10) represents the contribution of the reference system, which is taken as a hard sphere system, the second term is the perturbation contribution obtained by considering the dispersion forces (LJ) and dipoledipole interaction contributions via the expression:

$$
\mu_{t}^{P e r}=4 \pi \rho \int_{0}^{n} u(r) g^{h s}(r) r^{2} d r
$$

where $u(r)$ is the interaction energy as a function of inter-molecular distances, $g^{k s}(r)$, the radial distribution function of the hard sphere reference system. A rigorous expression for $g^{h s}(r)$ can be employed to obtain an analytical equation for the perturbation contribution (Khoshkbarchi and Vera, 1998). For practical applications, however, this treatment did not improve the results. In this work, a simple step function radial distribution function was used for $g^{h s}(r)$ : 


$$
g^{h s}(r)= \begin{cases}0, & r<\sigma \\ 1, & r \geq \sigma\end{cases}
$$

The advantages of eq.(4-10) are obvious: it is simple but has a strong theoretical background, and the modeling of results for both activity coefficients and solubility data are satisfactory. Unfortunately, dipole moments for amino acids are scarce and a quantum mechanical approach is needed to calculate this quantity, which is not convenient for engineering applications.

Khoshkbarchi and Vera (1996c) have extended the model to ternary systems. Their expression is lengthy and it is omitted here. In this work, for the ternary system we use a simpler version of the model.

\subsubsection{A New Model}

\section{Binary water - amino acid system}

The key quantity to derive this model is the perturbation potential. In a solution, in addition to the dispersion and the dipole-dipole interactions mentioned above, there are molecular interactions such as dipole induced interaction characterized by the polarizability, $\bar{\alpha}$, etc. A potential function, which considers all the three contributions in the primitive approximation, can be written as (Maitland et al., 1981):

$$
u(r)=4 \varepsilon\left[\left(\frac{\sigma}{r}\right)^{12}-\left(\frac{\sigma}{r}\right)^{6}\right]-\frac{2}{\left(4 \pi \varepsilon_{0} \varepsilon_{r}\right)^{2}}\left(\frac{D^{4}}{3 k T r^{6}}+\frac{D^{2} \bar{\alpha}}{r^{6}}+\cdots\right)
$$

where the first term is the Lennard-Jones potential for the dispersion interaction.

From eqs.(4-12) to (4-14), an expression for $\mu_{i}^{\text {per }}$ can be obtained, in which three terms are temperature-independent. For simplicity, the temperature-dependent terms can be neglected and combining the temperature-independent terms as shown in Appendix B, the perturbation contribution can be simply expressed as: 


$$
\ln \gamma_{r}^{\text {Per }}=-B \frac{4 \pi}{k T}\left(\rho \sigma^{3} \varepsilon\right)
$$

where constant $B$ includes $\mathrm{D}, \bar{\alpha}$ and other constants. It was found that for an amino acid in aqueous solutions, the constant $\mathrm{B}$ can be assigned the universal value $B=0.2$.

Therefore, for a binary amino acid + water system, the simplified model used in this work gives the following expression for the activity coefficient:

$$
\ln \gamma_{1}=\frac{8 \eta+9 \eta^{2}+3 \eta^{3}}{(1-\eta)^{3}}-\frac{0.8 \pi}{k T} \rho \sigma^{3} \varepsilon
$$

In this equation, molecules are characterized only by two parameters: $\varepsilon$ and $\sigma$ and no additional property is needed.

\section{Ternary amino acid - electrolyte - water system}

The extension of this model to ternary systems is straightforward (Kohshkbarchi and Vera 1996c). For the amino acid, the activity coefficient in the system is written as:

$$
\ln \gamma_{A}=\ln \gamma_{A}^{H S}+\ln \gamma_{A}^{P_{\text {er }}}
$$

and for electrolyte:

$$
\ln \gamma_{z}=\ln \gamma_{\Sigma}^{L R}+\frac{1}{v}\left[\ln \gamma_{S}^{H S}+\ln \gamma_{S}^{P_{e r}}-\lim _{\rho_{1} \rightarrow 0}\left(\ln \gamma_{S}^{H S}+\ln \gamma_{S}^{P_{\text {err }}}\right)\right]
$$

where the contribution to the mean ionic activity coefficient arising from the long range is exactly the value of the mean ionic activity coefficient in the binary electrolyte + water system at the same electrolyte molality as in the ternary system. Thus, $\ln y_{=}^{L R}$ is equal to $\ln \gamma \gamma_{=}^{(1)}$, and with the notation used here, eq.(4-18) can be rewritten as: 
$\ln \frac{\gamma_{ \pm}^{(2)}}{\gamma_{ \pm}^{(1)}}=\frac{1}{v}\left[\ln \gamma_{S}^{H S}+\ln \gamma_{S}^{\text {Per }}-\lim _{\rho_{1} \rightarrow 0}\left(\ln \gamma_{S}^{H S}+\ln \gamma_{S}^{\text {Per }}\right)+\ln \left(\frac{1+0.00 \mathrm{~L} M_{W} m_{S}}{1+0.00 \operatorname{Li} M_{W}\left(m_{S}+m_{A}\right)}\right)\right]$

where, as discussed previously, the last term is introduced to convert the activity coefficient from a molar fraction scale into a molality scale. Similarly, for the amino acid, eq.(4-17) is written as:

$\ln \frac{\gamma_{A}^{(2)}}{\gamma_{A}^{(1)}}=\ln \gamma_{A}^{H S}+\ln \gamma_{A}^{P_{A r}}-\lim _{\rho_{S} \rightarrow 0}\left(\ln \gamma_{A}^{H S}+\ln \gamma_{A}^{P_{t}}\right)+\ln \left(\frac{1+0.001 M_{W} m_{A}}{1+0.001 M_{W}\left(m_{S}+m_{A}\right)}\right)$

Various expressions for the activity coefficients of mixture of hard spheres are available in literanure. For instance, Taghikhani et al. (1999) recently proposed an expression which leads to improved results for the radial distribution function. For simplicity, in this work the expression proposed by Mansoori et al. (1971) was employed:

$$
\ln \gamma_{1}^{H S}=-\ln \left(1-\eta_{3}\right)+D+E+3 F
$$

with

$$
\begin{gathered}
D=\frac{\eta_{0} \sigma_{1}^{3}}{1-\eta_{3}}+\frac{3 \eta_{1} \eta_{2} \sigma_{1}^{3}}{\left(1-\eta_{3}\right)^{2}}+\frac{\eta_{2}^{3} \sigma_{1}^{3}\left(\hat{3}-\eta_{3}\right)}{\left(1-\eta_{3}\right)^{3}} \\
E=\frac{3 \eta_{2} \sigma_{1}+3 \eta_{1} \sigma_{1}^{2}}{1-\eta_{3}}+\frac{9 \eta_{2}^{2} \sigma_{1}^{2}}{2\left(1-\eta_{3}\right)^{2}}-\frac{\eta_{3}^{3} \sigma_{1}^{3}}{\eta_{3}^{3}}\left[2 \ln \left(1-\eta_{3}\right)+\frac{\eta_{3}\left(2-\eta_{3}\right)}{1-\eta_{3}}\right] \\
F=\frac{\eta_{2}^{2} \sigma_{1}^{2}}{\eta_{3}^{2}}\left[\ln \left(1-\eta_{3}\right)+\frac{\eta_{3}}{1-\eta_{3}}-\frac{\eta_{3}^{2}}{2\left(1-\eta_{3}\right)^{2}}\right]
\end{gathered}
$$

where

$$
\eta_{n}=\frac{\pi}{6} \sum_{k=1}^{2} \rho_{k} \sigma_{k}^{n} \quad(n=0,1,2,3)
$$


For the case of an amino acid + electrolyte + water system, in the primitive approach, only the amino acid and the electrolyte contribute to the sum.

Now we need an expression for the perturbation term. For this purpose, eq.(4-15) is extended to ternary systems. The chemical potential based on the first order BarkerHenderson perturbation theory is given by (Tiepel and Gubbins, 1973):

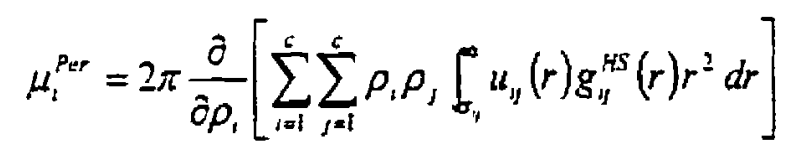

where $c$ is the total number of components. The following mixing rules are used for the molecular size and energy parameters:

$$
\begin{aligned}
& \sigma_{A S}=\sigma_{s t}=\frac{1}{2}\left(\sigma_{A}+\sigma_{s}\right)\left(\delta^{(0)}+\delta^{(1)} \rho_{A} \rho_{s}\right) \\
& \varepsilon_{. A S}=\varepsilon_{s i}=\sqrt{\varepsilon_{t} \varepsilon_{s}}
\end{aligned}
$$

The two constants $\left(\delta^{(0)}\right.$ and $\delta^{(l)}$ ) are adjustable parameters to be obtained from the measured activity coefficients data for the ternary system. As shown in appendix $C$, the perturbed activity coefficients for amino acid and electrolyte are given by eq.(4-29) and (4-30), respectively.

$$
\begin{aligned}
& \ln \gamma_{A} \rho_{t}=-\frac{0.8 \pi}{k T}\left[\rho_{A} \varepsilon_{A t} \sigma_{A t}^{j}+\rho_{S} \varepsilon_{A S} \sigma_{A S}^{j}+3 \rho_{A} \rho_{S} \varepsilon_{A S} \sigma_{A S}^{2}\left(\frac{\hat{\sigma} \sigma_{A S}}{\partial \rho_{A}}\right)\right] \\
& \ln \gamma_{S}^{P e r}=-\frac{0.8 \pi}{k T}\left[\rho_{S} \varepsilon_{S S} \sigma_{S S}^{3} \div \rho_{A} \varepsilon_{A S} \sigma_{A S}^{j}+3 \rho_{A} \rho_{S} \varepsilon_{. A S} \sigma_{.4 S}^{2}\left(\frac{\partial \sigma_{A S}}{\partial \rho_{S}}\right)\right]
\end{aligned}
$$

where:

$$
\begin{aligned}
& \frac{\partial \sigma_{A S}}{\partial \rho_{A}}=\frac{1}{2}\left(\sigma_{A}+\sigma_{S}\right) \delta^{(l)} \rho_{S} \\
& \frac{\partial \sigma_{A S}}{\partial \rho_{S}}=\frac{1}{2}\left(\sigma_{A}+\sigma_{S}\right) \delta^{(1)} \rho_{A}
\end{aligned}
$$


As shown in Appendix D, the activity coefficients given by eqs.(4-29) and (4-30) satisfy the following cross differential relation:

$$
\left(\frac{\partial \ln \gamma_{A}^{p_{e r}}}{\partial \rho_{S}}\right)_{T, \rho_{1}}=\left(\frac{\partial \ln \gamma_{S}^{\rho_{s e r}}}{\partial \rho_{A}}\right)_{T, D_{S}}
$$

The molecular parameters for electrolyte are calculated from those of the ions by the following mixing rules (Kohshkbarchi and Vera. 1997):

$$
\begin{aligned}
& \varepsilon_{s}=\sqrt{\varepsilon_{-} \varepsilon_{-}} \\
& \sigma_{s}=\frac{1}{2}\left(\sigma_{-}+\sigma_{-}\right)
\end{aligned}
$$

The values of parameters of ions and electrolytes used in this work are listed in Table 4.1. For $\mathrm{NO}_{3}$, the energy parameter was calculated with the following equation (Khoshkbarchi and Vera, 1997):

$$
\varepsilon_{1} / k=2.2789 \times 10^{-11} \bar{\alpha}_{1}^{1.5} \eta_{1}^{0.5} / \sigma_{1}^{6}
$$

where the polarizability $(\bar{\alpha})$ and total number of electrons $\left(\eta_{1}\right)$ equal $4.37 \times 10^{-30}\left(\mathrm{~m}^{3}\right)$ (Zaytev and Aseyev, 1992) and 32, respectively.

Table 4.1 Values of pure component parameters of ions and electrolytes

\begin{tabular}{llllll}
\hline & $\mathrm{Na}^{+}$ & $\mathrm{K}^{+}$ & $\mathrm{NO}_{3}^{-}$ & $\mathrm{KNO}_{3}$ & $\mathrm{NaNO}_{3}$ \\
\hline$\sigma\left(\times 10^{-10} \mathrm{~m}\right)$ & $1.90^{(1)}$ & $2.66^{(1)}$ & $4.28^{(2)}$ & 3.47 & 3.09 \\
$\varepsilon k(\mathrm{~K})$ & $96.0^{(1)}$ & $214.0^{(1)}$ & 191.6 & 202.5 & 135.6 \\
\hline
\end{tabular}

(1): Khoshkbarchi and Vera (1997); (2) Zaytev and Aseyev, (1992). 


\subsection{Calculation Results}

\subsubsection{Binary systems}

For testing the new model, eq.(4-16) was used to correlate the activity coefficient of amino acid in aqueous solution. The two parameters: $\sigma$ and $\varepsilon$, were regressed from experimental data (Fasman, 1976). According to the definition of molality of amino acid, $m_{A}$, the number density used in the equation is calculated by the following equation:

$$
\rho_{d}=1000 m_{d} N_{a}
$$

The activity coefficient based on molality is changed into the one based on molar fraction by the following equation:

$$
\gamma_{A}^{(x)}=\gamma_{A}^{(m)}\left(1+0.001 M_{A} m_{A}\right)
$$

The objective function used is given by:

$$
O F_{.}=\sum_{i}\left(\gamma_{i}^{\exp }-\gamma_{i}^{\operatorname{cad}}\right)_{i}^{2}
$$

Table 4-2 lists the results for 7 systems. Figure 4.1 depicts the results for 4 systems.

Table 4.2 Calculation results for activity coefficients of amino acids

\begin{tabular}{lrrr}
\hline System & $\varepsilon / \mathrm{K}(\mathrm{K})$ & $\sigma \times 10^{-10}(\mathrm{~m})$ & s.e.e \\
\hline Alanine & 365.9 & 3.94 & 0.0024 \\
Q-amino n-butyric acid & 341.8 & 4.14 & 0.0046 \\
Glycine & 1020.0 & 4.25 & 0.0094 \\
Proline & 231.8 & 3.84 & 0.0285 \\
DL-serine & 1205.0 & 4.28 & 0.0099 \\
Valine & 321.5 & 5.32 & 0.0066 \\
L-hydroxyproline & 441.8 & 3.57 & 0.0021
\end{tabular}

The standard error of estimate is defined as (Draper and Smith, 1981): s.e.e $=\sqrt{\sum_{i}\left(\gamma_{A}^{\text {cel }}-\gamma_{A}^{\text {exp }}\right)_{i}^{2} /\left(n_{D}-2\right)}$. 


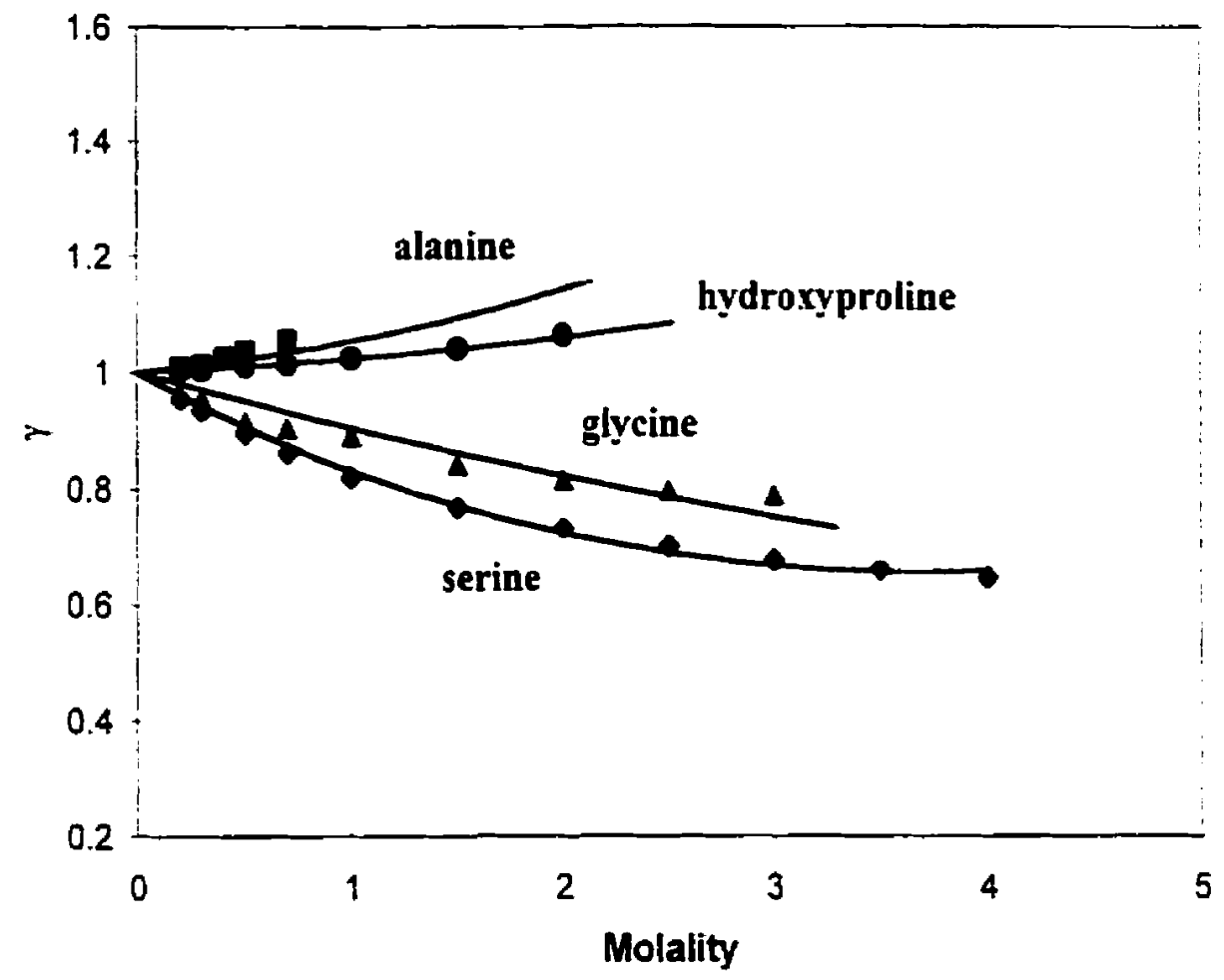

Figure 4.1 Correlation results for activity coefficients of amino acids in binary aqueous solutions 


\subsubsection{Ternary systems}

Both the Gibbs free energy model (Kohshibarchi and Vera, 1996a) and the new simplified perturbation model were used to correlate the 4 ternary systems measured in this work. The objective function used to regress the parameters is defined as:

$O F_{=}=\sum_{1}\left[\left(\gamma_{ \pm}^{(3)} / \gamma_{=}^{(1)}\right)_{1}^{\exp }-\left(\gamma_{ \pm}^{(2)} / \gamma_{ \pm}^{(1)}\right)_{r}^{(a t}\right]^{2}$

Table 4.3 lists the parameters and the results obtained using the Gibbs free energy model.

Table 4.3 Results for temary systems by Gibbs free energy model

$\begin{array}{llllll} & \tau_{A, S} & \tau_{S, H} & \tau_{A, H} & \tau_{W, A} & \text { s.e.e }\end{array}$

$\begin{array}{llllll}\text { glycine- } \mathrm{KNO}_{3}-\mathrm{H}_{2} \mathrm{O} & -0.0472 & 0.0726 & -1.9610 & 4.5801 & 0.0341 \\ \text { DL-serine- } \mathrm{NaNO}_{3}-\mathrm{H}_{2} \mathrm{O} & -0.5607 & 0.3311 & -2.0771 & 3.8481 & 0.0067 \\ \text { DL-serine- } \mathrm{KNO}_{3}-\mathrm{H}_{2} \mathrm{O} & -0.5166 & 0.3042 & -2.0771 & 3.8481 & 0.0106 \\ \text { DL-valine- } \mathrm{NaNO}_{3}-\mathrm{H}_{2} \mathrm{O} & -0.8756 & 0.5346 & -0.8496 & 1.4371 & 0.0092\end{array}$

NRTL parameters: $\tau_{A, H}$ and $\tau_{W, A}$ from amino acid + water systems (Fasman, 1976); $\tau_{s, s}$ and $\tau_{s, y}$ from ternary systems (this work).

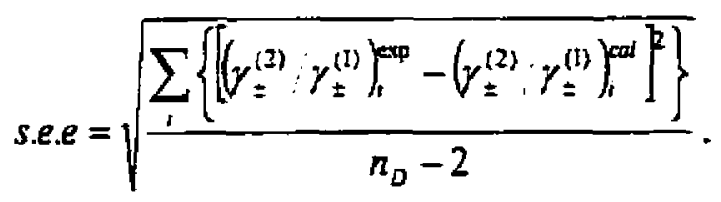


Table 4.4 lists the results obtained using the simplified perturbation model. The parameters used for the amino acids are those from Table 4.2, and for the electrolytes those from Table 4.1. Figure 4.2 depicts the results for Glycine $+\mathrm{KNO}_{3}+$ water system obtained with the new simplified perturbation model using two adjustable parameters. The results obtained with keeping one or two parameters constant, and also those obtained with the Gibbs free energy model, are almost not distinguishable from those presented when plotted in the figure.

For testing the predictive features of the model, the two parameters were taken as fixed values for all systems: $\delta^{(0)}=1.6$ and $\delta^{(1)}=-0.1 \times N_{u}^{2} \times 10^{6}$. The root mean square deviations are also listed in Table 4.4. As is seen from the table, the prediction results are acceptable and comparable with the results obtained from the Gibbs free energy model.

Table 4.4 Results for temary systems by perturbation model

\begin{tabular}{lllll}
\hline System & $\delta^{(0)}$ & $\delta^{(1)} / \mathrm{N}_{3}^{2} \times 10^{6}$ & s.e.e & s.e.e. \\
\hline glycine- $\mathrm{KNO}_{3}-\mathrm{H}_{2} \mathrm{O}$ & 1.4984 & -0.0673 & 0.0115 & 0.0334 \\
DL-serine $-\mathrm{NaNO}_{3}-\mathrm{H}_{2} \mathrm{O}$ & 1.6572 & -0.3615 & 0.0036 & 0.0066 \\
DL-serine- $\mathrm{KNO}_{3}-\mathrm{H}_{2} \mathrm{O}$ & 1.5363 & -0.6855 & 0.0053 & 0.0228 \\
DL-valine- $\mathrm{NaNO}_{3}-\mathrm{H}_{2} \mathrm{O}$ & 1.5680 & -0.2363 & 0.0076 & 0.0106
\end{tabular}

a: prediction results with $\delta^{(0)}=1.6$ and $\delta^{(1)}=-0.1 \times N_{u}^{2} \times 10^{6}$.

Calculations adjusting one of the parameters and keeping the other constant produced results that only slightly better than those obtained fixing the values of both parameters. As seen from Tables 4.3 and 4.4 , both methods give satisfactory correlation resuits for the four ternary systems. Therefore, a two parameter model suffices for practical applications. The perturbation model gives somewhat better results and can be used as prediction model with acceptable accuracy. 


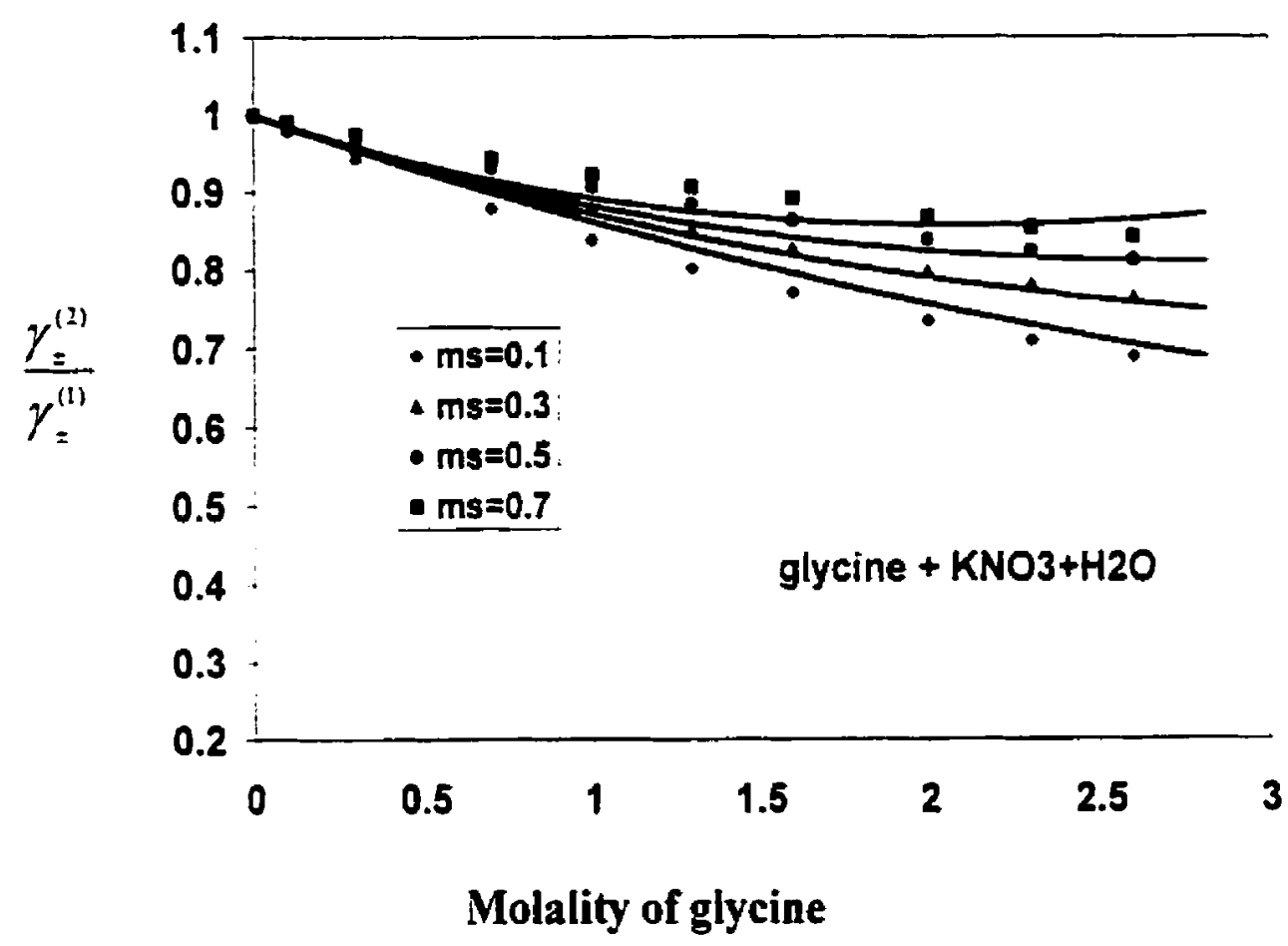

Figure 4.2 Correlation results by the simplified perturbation model for the mean activity coefficient of $\mathrm{KNO}_{3}$ in ternary system $\left(\mathrm{KNO}_{3}+\right.$ glycine $\left.+\mathrm{H}_{2} \mathrm{O}\right)$. 


\subsection{Modeling the Solubility of Amino Acid in Water}

The solubility of amino acids in water is an important information for separation purposes. For an accurate correlation of this property, a reliable activity model is required. As a further application of the model proposed for binary amino acid + water system, eq.(4-16). The solubility of amino acid in water was correlated for some systems where both activity coefficient and solubility data are available (Fasman, 1976).

\section{Theoretical background}

The above modeling for the activity coefficient was performed at a constant temperature $(298.15 \mathrm{~K})$. But for the solubility correlation. wide temperature ranges (273.15 to $373.15 \mathrm{~K}$ ) have to be considered. For a better representation of the temperanure dependence of the activity coefficients, the effective hard sphere diameter (EHSD) approach was employed. In this approach, the molecular diameter is considered to be a function of temperature and density. For simplicity, in this work we take only the temperature effect into account. Various expressions for the EHSD are available in literanure (Ben-Amotz and Herschbach, 1990). Here the following expression obtained by Ben-Amotz and Herschbach (1990) based on the molecular simulation results was adopted:

$$
\sigma_{e}=1.1532 \sigma\left[1+\left(\frac{T^{*}}{0.527}\right)^{1.2}\right]^{-1,6}
$$

where the subscript ' $e$ ' refers effective hard sphere diameter. The reduced temperature is defined as:

$$
T^{*}=\frac{T}{\varepsilon_{i} k}
$$

Now the reference term of the activity coefficient is expressed as: 


$$
\ln \gamma_{1}^{\text {Ref }}=\frac{8 \eta_{e}+9 \eta_{e}^{2}+3 \eta_{e}^{3}}{\left(l-\eta_{e}\right)^{3}}
$$

where

$$
\eta_{e}=\frac{1}{6} \pi \rho \sigma_{e}^{3}
$$

The perturbation term is the same as eq.(4-15). The molecular size and energy parameters are taken from Table 4.2.

For the system considered here, when it is in equilibrium with a solid phase of pure amino acid:

$$
f_{i}^{L}=f_{t}^{s}
$$

If the standard state of the liquid fugacity is $f_{.4}^{0 L}$. then eq.(4-45) can be written as:

$$
x_{A}{ }_{A} f_{A}^{O L}=f_{i}^{j}
$$

From the definition of fugacity (Koshkbarchi and Vera, 1996d):

$$
\frac{f_{A}^{S}}{f_{. t}^{0 L}}=\exp \left(\frac{\Delta s}{R}-\frac{\Delta h}{R T}\right)
$$

where $\Delta s$ and $\Delta h$ are the change in the molar entropy and enthalpy of the amino acid, respectively, from the standard liquid state to the solid state, and $\mathrm{R}$ is the gas constant. Finally, the solubility of amino acid in water is estimated from the following equation:

$$
x_{i} y_{1}=\exp \left(\frac{\Delta s}{R}-\frac{\Delta h}{R T}\right)
$$

The two quantities $\Delta s / R$ and $\Delta h / R$ are regressed from the solubility data (Fasmann, 1976). 


\section{Calculation results}

Eqs.(4-48) and (4-43) with (4-15) $(B=-0.2)$ were used to correlate the solubility data. In eq.(4-48) at each solubility $S$ ( $g / k g-s o l v e n t)$, the number density is calculated with:

$$
\rho_{d}=1000 N_{a} S / M_{d}
$$

where $M_{A}$ is the molecular weight of the amino acid. The relation between mol fraction and $S$ is given by:

$$
x_{A}=\frac{S / M_{A}}{S / M_{A}+1000 / M_{W}}
$$

Table 4.5 lists the results for six systems, and Figure 4.3 shows the results for four systems. Since the values of the solubility are big, absolute average deviation (AAD) is used as the criterion of the correlation accuracy. As seen from the Table 4-5 and Figure 4.3 , the results are satisfactory.

Table 4-5 Calculation results for solubility of amino acids

\begin{tabular}{lccc}
\hline System & $\Delta \mathrm{s} / \mathrm{R}$ & \multicolumn{1}{c}{$\Delta \mathrm{h} / \mathrm{R}(\mathrm{K})$} & $\mathrm{AAD}$ \\
\hline Alanine & 0.8077 & 1254.9 & 2.81 \\
Glycine & 2.0888 & 1485.0 & 4.26 \\
Proline & 0.9102 & 744.9 & 1.48 \\
DL-serine & 4.4880 & 2707.6 & 0.44 \\
Valine & -0.6674 & 1138.0 & 7.14 \\
L-hydroxyproline & -0.1117 & 833.7 & 2.37 \\
\hline \multirow{2}{*}{$A A D=\frac{100}{N} \sum_{i=1}^{N} \frac{\left|S_{i}^{\text {cop }}-S_{i}^{\text {cad }}\right|}{S_{i}^{\text {cap }}}}$, & \multirow{2}{*}{ S=solubility in g/kg (solvent) }
\end{tabular}




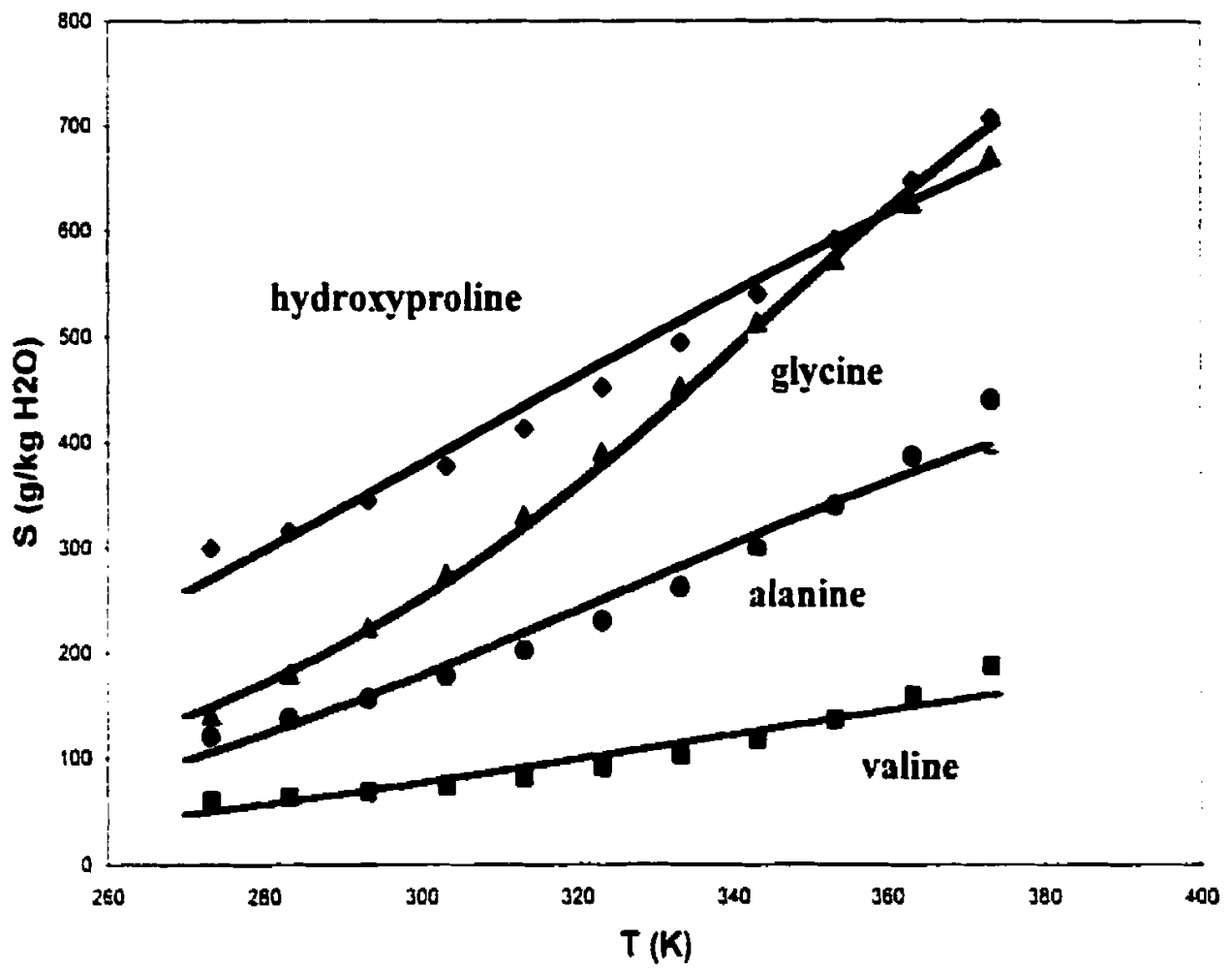

Figure 4.3 Correlation results for solubility of amino acids in $\mathrm{H}_{2} \mathrm{O}$ 


\section{CHAPTER 5: CONCLUSIONS, CONTRIBUTIONS TO KNOWLEDGE AND SUGGESTIONS FOR FUTURE WORK}

\subsection{Conclusions}

The mean ionic activity coefficients of the electrolyte and activity coefficients of the amino acids were measured at $298.15 \mathrm{~K}$ using the electrochemical method for the following four systems: $\mathrm{DL}$-serine $+\mathrm{NaNO}_{3}+$ Water, $\mathrm{DL}$-valine $+\mathrm{NaNO}_{3}+$ Water; $\mathrm{DL}-$ serine $\div \mathrm{KNO}_{3} \div$ Water; glycine $\div \mathrm{KNO}_{3}+$ Water.

The activity coefficients of DL-serine in DL-serine $+\mathrm{KNO}_{3}+$ Water system were also measured at $298.15 \mathrm{~K}$ using isopiestic method. The results were compared with those obtained by electrochemical method. The trends of the concentration effect on the activity coefficients from the two methods are the same. The possible error sources and advantages and disadvantages of the two methods were discussed.

The data measured for the temary systems were correlated using the Gibbs free energy model proposed by Khoshbarchi and Vera (1996a) with the NRTL equation. Among the six binary parameters, two binary parameters were obtained from the amino acid $\div$ water system, two parameters were obtained from temary data, and symmetrical relations were assumed for other two parameters.

A new model based on simplified perturbation theory was proposed. This model was used to correlate the measured data for the four systems. Two adjustable parameters were regressed from the ternary system, while the other parameters were obtained from binary amino acid + water systems and from the data of ions. The major advantage of the new model is the simplicity of the formulation. In addition, the amino acid molecules are characterized only by a size and an energy parameter, and no other property is required for the correlation. The results of the correlation are slightly better than those obtained from the Gibbs free energy model. 
The new model was also used to correlate the activity coefficients and solubilities of amino acids for some binary aqueous solution reported in literature (Fasnman, 1976). Satisfactory results were obtained.

\subsection{Contributions to Knowledge}

New data for mean ionic activity coefficients of electrolytes and for activity coefficients of amino acids in four ternary systems at $298.15 \mathrm{~K}$ were measured. The effects of the concentration of the electrolyte and the amino acid were determined.

A new model based on a simplified perturbation theory was proposed and tested with the experimental measured in this work and from literanure. The model is easy to use, and no additional molecular data is needed for the calcujations. The new model was applied to correlate the activity coefficients for binary (amino acid $\div$ water) and ternary (amino acid $\div$ electrolyte + water) systems and solubilities of amino acid in binary aqueous solutions.

\subsection{Suggestions for Future Work}

It would be of interest to measure the temperature effect on the activity coefficients, using the electrochemical and the isopiestic methods, over the temperature range from 298.15 to $323.15 \mathrm{~K}$.

For comparison with the results from the electrochemical method, activity coefficients for more systems should be measured by the isopiestic method. The set up for this method can be further improved.

Based on some theoretical considerations, it could be desirable to develop a new model which can predict, with some accuracy, the activity coefficients for ternary systems using only parameters obtained from binary systems. For example, in the model based on perturbation theory, generalized mixing rules may be obtained after employing the model for many systems. New mixing rules may be necessary. 


\section{REFERENCES}

Ben-Amotz, D., Herschbarch, D. R., Estimation of Effective Diameter for Molecular Fluids, J. Phys. Chem., 94, 1038. 1990.

Bower, V. E., Robinson, R. A., Thermodynamics of the Ternary Systems: WaterGlycine-Patassium Chloride at $25 \mathrm{C}$ from Vapor Pressure Measurements, J. Res. Natl. Bureau of Standards. 69A, 131, 1965.

Butler, J. N., lonic Equilibrium: Solubility and pH Calcularions, John Willey \& Sons, New York, 1998.

Briggs, C. C., Lilley, T. H., Rutherford, J., Woodhead, S., The Activity of Calcium Chloride in Aqueous Solutions of Some Amino Acids at 25 C. J. Solution Chem., 3, 649. 1974.

Bromley, L. A., Thermodynamic Properties of Strong Electrolytes in Aqueous Solutions, AIChE J., 19, 313, 1973.

Davies, C. W., Ion Association. Butterworth, London, 1962.

Draper, N. R., Smith, H., Applied Regression Analysis, $2^{\text {nd }}$ ed., John Wiley \& Sons, Inc., New York, 1981.

Fasman, G. D., Handbook of Biochemisry and Molecular Biology, $3^{\text {rd }}$ ed., Physical and Chemical Data. Vol. i CRC Press. Cleveland, 1976.

Haghtalab, A., Thermodynamics of Aqueous Electrolyte Solutions, Ph. D. Thesis, Dept. of Chem. Eng., McGill University, Montreal, 1990. 
References.

Haghtalab, A., Vera, J. H., Mean Activity Coefficients in Ternary NaCL-NaNO ${ }_{3}-\mathrm{H}_{2} \mathrm{O}$ and $\mathrm{NaBr}-\mathrm{NaNO}_{3}-\mathrm{H}_{2} \mathrm{O}$ systems at $298.15 \mathrm{~K}, J$. Chem. Eng. Data, 36, 332, 1991.

Kelley, B. P. Lilley, T. H., Aqueous Solutions Containing Amino Acids and Peptides, V, Chem. Soc. J., Faraday Trans. I., 74, 2771, 1978.

Khoshkbarchi, M. K., Vera, J. H., Measurement and Modeling of Activities of Amino Acid in Aqueous Salt Systems, AIChE J., +2, 2354, 1996a.

Khoshkbarchi, M. K., Vera. J. H.. Measurement of Activity Coefficients of Amino Acids in Aqueous Electrolyte Solutions: Experimental Data for the Systems $\mathrm{H}_{2} \mathrm{O}+\mathrm{NaCl}+$ Glycine and $\mathrm{H}_{2} \mathrm{O}+\mathrm{NaCl}+\mathrm{DL}$-Alanine at $25^{\circ} \mathrm{C}$, IEC Res.. 35, 2735, 1996b.

Khoshkbarchi, M. K., Vera, J. H., A Perturbed Hard-Sphere Model with Mean Spherical Approximation for the Activity Coefficients of Amino Acids in Aqueous Solutions, IEC Res., 35, 4755, $1996 \mathrm{c}$.

Khoshkbarchi, M. K., Vera. J. H., A Simplified Perturbed Hard-Sphere Model for the Activity Coefficients of Amino Acids and Peptides in Aqueous Solutions, IEC Res., 35, $4320,1996 d$.

Khoshkbarchi, M. K., Vera. J. H., Activity Coefficients of DL-Valine in Aqueous Solutions of $\mathrm{KCl}$ at $25^{\circ} \mathrm{C}$, Measurement with Ion Selective Electrodes and Modeling, $J$. Solution Chem., 25, 865, $1996 \mathrm{e}$.

Khoshkbarchi, M. K., Vera, J. H., Measurement and Correlation of lon Activity Coefficients in Aqueous Single Electrolyte Solution, AIChE J., 42, 249, $1996 \mathrm{f}$. 
References.

Khoshkbarchi, M. K., Vera, J. H., Effect of $\mathrm{NaCl}$ and $\mathrm{KCl}$ on the Solubility of Amino Acids in Aqueous Solutions at 298.2 K: Measurements and Modeling, IEC Res., 36, $2445,1997$.

Khoshkbarchi, M. K., Soto-Campos, A. M., Vera, J. H., Interaction of DL-serine and Lserine with $\mathrm{NaCl}$ and $\mathrm{KCl}$ in Aqueous Solutions, J. Solution Chemistry, 26, 914, 1997.

Khoshkbarchi, M. K., Vera. J. H., A Theoretical Improved Perturbation Model for Activity Coefficients of Amino Acids and Peptides in Aqueous Solutions, IEC Res., 37, $3052,1998$.

Lewis, G. N., Randall. M., Thermodynamics, McGraw-Hill, New York, 1961.

Lin, D.-D., Mei. L.-H.. Zhu. Z.-Q., Han, Z.-X., An Improved Isopiestic Method for Measurement of water Activities in Aqueous Polymer and Salt Solution. Fluid Phase Equilibria. 118.241, 1996.

Maitland, G. C., Rigby, M.. Smith. E. B., Wakeham, W. A., Intermolecular Forces, Clarendon Press, Oxford. UK. 1981.

Mansoori, G. A., Carnahan, N. F., Starling, K. E., Leland, T. W., Equilibrium Thermodynamic Properties of Mixtures of Hard Spheres, J. Chem. Phys., 54, 1523, 1971.

Ochs, L. R., Kabiri-Badr, M., Cabezas, H. Jr., An Improved Isopiestic Method to Determine Activities in Multicomponent Mixtures, AIChE J., 36, 1908, 1990.

Park, H., Englezos, P.. Osmotic Coefficient Data for $\mathrm{Na}_{2} \mathrm{SiO}_{3}$ and $\mathrm{Na}_{2} \mathrm{SiO}_{3}-\mathrm{NaOH}$ by an Isopiestic Method and Modeling Using Pitzer's Model, Fluid Phase Equilibria. 153, 87, 1998. 
References.

Phang, S., Steel, B. J., Activity Coefficients from e.m.f. measurements using cationresponsive glass electrode. $\mathrm{NaCL}+$ Glycine + Water at $273.13,283.15,298.15$, and $323.15 \mathrm{~K}$, J. Chem. Thermodynamics, 6. 537, 1974.

Pradhan, A. A., Vera, J. H., Effect of Acids and Bases on the Solubility of Amino Acids, Fluid Phase Equilibria, 152, 121, 1998.

Robinson, R. A., Stokes, R. H., Electrolyte Solutions, $2^{\text {nd }}$ ed., Butterworth Scientific Publications, London, 1959.

Rodriquez-Raposo, R. Fernandez-Merida. Esteso, M. A., Activity Coefficients in (Electolyte + Amino Acid) (Aq). J. Chem. Thermodynamics. 26. 1121. 1994.

Scatchard, G., Hamer, W. J.. Wood, S. E., Isotonic Solutions 1. J. Am. Chem. Soc., 60, $3061,1938$.

Schrier, E. E., Robinson, R. A., A Study of Free Energy Relationships in Some Amino Acid-Sodium-Water Systems, J. Biol. Chem., 246, 2870, 1971.

Schrier, E. E., Robinson. R. A.. Free Energy Relationships in Aqueous Amino Acid and Peptide Solutions Containing Sodium Chloride, J. Solution Chem., 3, 493, 1974.

Silverberg, M., Activity Coefficients of DL-serine in Aqueous $\mathrm{KNO}_{3}$, Project report (302-495B), 1998, Chem. Eng. Dept., McGill University.

Sinclair, D. A., A Simple Method for Accurate Determination of Vapor Pressures of Solutions, J. Phys. Chem., 37, 495, 1933. 
References.

Skoog, D. A., Leary, J. J., Principles of Instrumental Analysis, Fort worth, Saunders College Pub., 1992.

Soto-Campos, A. M., Khoshkbarchi, M. K., Vera, J. H., Interaction of DL-threonine with $\mathrm{NaCl}$ and $\mathrm{NaNO}_{3}$ in Aqueous Solutions: e.m.f. Measurements with Ion-selective Electrodes, J. Chem. Thermodynamics. 29, 609, 1997a.

Soto-Campos, A. M., Khoshkbarchi, M. K., Vera, J. H., Activity Coefficients of the Electrolyte and the Amino Acid in Water $\div \mathrm{NaNO}_{3} \div$ Glycine and Water $+\mathrm{NaCl}+\mathrm{DL}-$ methionine Systems at $298.15 \mathrm{~K}$. Biophysical Chemisrry, 67, 97, $1997 \mathrm{~b}$.

Soto-Campos, A. M., Khoshkbarchi, M. K., Vera, J. H., Effect of the Anion and the Cation of an Electrolyte on the Activity Coefficient of DL-alanine in Aqueous Solutions, Fluid Phase Equilibria. 142, 193, 1998.

Taghikhani, V.. Khoshkbarchi. M. K., Vera, J. H., On the Expression for the Chemical Potential in Mixtures of Hard Spheres. Fluid Phase Equilibria. 165, 141, 1999.

Tiepel, E. W., Gubbins. K. E., Thermodynamic Properties of Gases Dissolved in Electrolyte Solutions, Ind. Eng. Chem. Fundam. 12, 18, 1973.

Thiessen, D. B., Wilson, A. J., An Isopiestic Method for Measurement of Electrolyte Activity Coefficients, AIChEJ., 33, 1926, 1987.

Zaytsev, I. D., Aseyev, M. A., Properties of Aqueous Solutions of Electrolytes, CRC Press, Boca Raton, 1992. 


\section{APPENDICES}

\section{A $\Delta \mathbf{E}$ Data by Electrochemical Method}

Table A.1 $\Delta E$ data for $\mathrm{NaNO}_{3} \div \mathrm{DL}$-serine $+\mathrm{H}_{2} \mathrm{O}$ system

\begin{tabular}{llllll}
\hline $\begin{array}{c}\mathrm{m} \mathrm{NaNO} \\
\mathrm{c}_{3} \Rightarrow\end{array}$ & 0.1 & 0.3 & 0.5 & 0.7 & 1.0 \\
\hline $\begin{array}{c}\mathrm{m} D \text {-serine } \\
\Downarrow\end{array}$ & \multicolumn{5}{c}{$\Delta \mathrm{E}$} \\
\hline 0 & 171.3 & 221.6 & 243.6 & 258.1 & 273.5 \\
0.05 & 170.7 & 221.1 & 243.2 & 257.9 & 273.3 \\
0.1 & 170.2 & 220.8 & 242.9 & 257.6 & 273.1 \\
0.15 & 169.7 & 220.4 & 242.6 & 257.4 & 272.8 \\
0.2 & 169.3 & 220.0 & 242.3 & 257.1 & 272.6 \\
0.25 & 168.9 & 219.7 & 242.0 & 256.8 & 272.3 \\
0.3 & 168.4 & 219.3 & 241.6 & 256.5 & 272.1 \\
0.35 & 168.0 & 218.9 & 241.4 & 256.3 & 271.9 \\
0.4 & 167.6 & 218.6 & 241.1 & 256.0 & 271.7
\end{tabular}

Table A.2 $\Delta$ E data for $\mathrm{NaNO}_{3} \div \mathrm{DL}$-valine $+\mathrm{H}_{2} \mathrm{O}$ system

\begin{tabular}{cccccc}
\hline $\mathrm{m} \mathrm{KNO}_{3} \Rightarrow$ & 0.1 & 0.3 & 0.5 & 0.7 & 1.0 \\
\hline $\begin{array}{c}\mathrm{m} \mathrm{DL} \text {-valine } \\
\Downarrow\end{array}$ & \multicolumn{5}{c}{$\Delta \mathrm{E}$} \\
\hline 0 & 174.4 & 225.4 & 248.2 & 262.6 & 278.0 \\
0.1 & 174.3 & 225.3 & 248.3 & 262.8 & 278.2 \\
0.2 & 174.0 & 225.2 & 248.2 & 262.9 & 278.4 \\
0.3 & 173.8 & 225.1 & 248.2 & 262.8 & 278.5 \\
0.4 & 173.5 & 224.8 & 248.1 & 262.8 & 278.6 \\
0.5 & 173.2 & 224.7 & 248.2 & 262.8 & 278.6
\end{tabular}


Appendices

Table A.3 $\triangle E$ data for $\mathrm{KNO}_{3}+\mathrm{DL}$-serine $+\mathrm{H}_{2} \mathrm{O}$ system

\begin{tabular}{lrrrr}
\hline $\mathrm{m} \mathrm{KNO}_{3} \Rightarrow$ & 0.1 & 0.3 & 0.5 & 0.7 \\
\hline $\begin{array}{c}\mathrm{m} \text { DL-serine } \\
\Downarrow\end{array}$ & \multicolumn{4}{c}{$\Delta \mathrm{E}$} \\
\hline 0 & -32.6 & 10.0 & 26.3 & 35.0 \\
0.01 & -32.8 & 9.9 & 26.3 & 35.0 \\
0.03 & -32.9 & 9.8 & 26.2 & 35.0 \\
0.05 & -33.0 & 9.7 & 26.2 & 34.9 \\
0.1 & -33.5 & 9.4 & 26.0 & 34.7 \\
0.15 & -33.9 & 9.2 & 25.8 & 34.6 \\
0.2 & -34.5 & 8.9 & 25.6 & 34.5 \\
0.25 & -34.9 & 8.6 & 25.4 & 34.3 \\
0.3 & -35.3 & 8.3 & 25.2 & 34.3 \\
0.35 & -35.7 & 8.0 & 25.0 & 34.1 \\
0.4 & -36.1 & 7.7 & 24.9 & 33.9
\end{tabular}

Table A.4 $\Delta \mathrm{E}$ data for $\mathrm{KNO}_{3} \div$ glycine $+\mathrm{H}_{2} \mathrm{O}$ svstem

\begin{tabular}{ccccc}
\hline $\mathrm{m} \mathrm{KNO}_{3} \Rightarrow$ & 0.1 & 0.3 & 0.5 & 0.7 \\
\hline $\begin{array}{c}\text { m glycine } \\
\Downarrow\end{array}$ & & & $\Delta \mathrm{E}$ & \\
\hline 0 & & & & \\
0.1 & -32.7 & 9.6 & 25.1 & 34.2 \\
0.3 & -35.3 & 8.9 & 24.6 & 33.9 \\
0.7 & -38.4 & 5.5 & 23.6 & 33.1 \\
1.0 & -40.5 & 4.0 & 20.8 & 31.7 \\
1.3 & -42.5 & 2.5 & 19.7 & 29.9 \\
1.6 & -44.2 & 1.3 & 18.7 & 29.2 \\
2.0 & -46.3 & -0.3 & 17.4 & 28.0 \\
2.3 & -47.8 & -1.2 & 16.7 & 27.3 \\
2.6 & -49.0 & -2.2 & 16.0 & 26.7
\end{tabular}




\section{B. Derivation of Eq.(4-15)}

The intermolecular force is composed of several parts: dispersion force, dipoledipole interaction force, and induction force, etc. The dispersion can be expressed by the Lennard-Jones potential. The dipole-dipole interaction potential and induction potential for a pure substance (here in a binary amino acid + water system, the amino acid acts like a 'pure' substance in a background of continuum) are given by eqs.(B-1) and (B-2), respectively (Maitland et al., 1981).

$$
\begin{aligned}
& u_{D D}(r)=-\frac{2}{3} \frac{D^{s}}{\left(4 \pi \varepsilon_{0} \varepsilon_{r}\right)^{3} k T r^{6}} \\
& u_{\text {trd. } . D D}(r)=-\frac{2 \bar{\alpha} D^{2}}{\left(4 \pi \varepsilon_{0} \varepsilon_{r}\right)^{2} r^{6}}
\end{aligned}
$$

where $\bar{\alpha}$ is the polarizability. Combining the all interaction potentials and inserting the potential and eq.(4-13) into eq.(4-12), the perturbed chemical potential is given by:

$$
\begin{aligned}
\mu_{1}^{P_{e r}} & =4 \pi \rho \int_{\sigma}^{\sigma} u(r) r^{2} d r \\
& =4 \pi \rho \int_{\sigma}^{\infty}\left\{4 \varepsilon\left[\left(\frac{\sigma}{r}\right)^{i 2}-\left(\frac{\sigma}{r}\right)^{\sigma}\right]-\frac{2}{\left(4 \pi \varepsilon_{0} \varepsilon_{r}\right)^{2}}\left(\frac{D^{4}}{3 k T r^{6}}+\frac{D^{i} \bar{\alpha}}{r^{6}}\right)\right\} r^{2} d r
\end{aligned}
$$

After integration and rearrangement, and using the relation,

$$
\mu_{i}^{P e r}=k T \ln \gamma_{i}^{\text {Per }}
$$

we have

$$
\ln \gamma_{i}^{P a r}=-\frac{4 \pi \rho \sigma^{3} \varepsilon}{k T} B
$$


where $B$ is defined as

$$
B=\frac{8}{9}+\frac{2}{3\left(4 \pi \varepsilon_{0} \varepsilon_{r}\right)^{2}}\left(\frac{D^{+}}{3 k T}+D^{2} \bar{\alpha}\right) \frac{1}{\sigma^{6} \varepsilon}
$$

Strictly, $B$ is a function of $D, \bar{\alpha}$ and $T$. In this work, we found it suffices to assume $B=$ 0.2 in our correlation. This significantly simplified the model.

\section{Derivation of the Perturbation Term for Mixtures}

The perturbed chemical potential is given by eq.(4-26). As in the 'pure' amino acid case, a step function is used for the radial distribution function. For illustration purpose, only Lennard-Jones potential is considered here (since a constant $(0.2)$ will be finally adopted as the case discussed in Appendix B):

$$
u_{i j}^{\nu}(r)=4 \varepsilon_{i j}\left(\frac{\sigma_{i y}^{12}}{r^{12}}-\frac{\sigma_{i t}^{6}}{r^{6}}\right)
$$

In our application, the solution is considered as 'binary', after integration the double summation term is given by:

$$
\text { [double sum] }=-\frac{8}{9}\left(\rho_{A}^{2} \varepsilon_{A s} \sigma_{A d}^{3}+2 \rho_{A} \rho_{s} \varepsilon_{d S} \sigma_{A S}^{3}+\rho_{s}^{2} \varepsilon_{s S} \sigma_{s S}^{3}\right)
$$

Assuming (1) symmetrical relations: $\varepsilon_{A s}=\varepsilon_{S i}$ and $\sigma_{A S}=\sigma_{S A}$, (2) the molecular energy parameters are independent of density, while the size parameters are the functions of density given by eq.(4-27), after rearrangement, the activity coefficients of amino acid and electrolyte are given by following equations:

$$
\ln \gamma_{d}^{P_{A}}=-\frac{B \pi}{k T}\left[\rho_{d} \varepsilon_{d A} \sigma_{d A}^{3}+\rho_{S} \varepsilon_{A S} \sigma_{d S}^{3}+3 \rho_{A} \rho_{S} \varepsilon_{A S} \sigma_{A S}^{2}\left(\frac{\partial \sigma_{A S}}{\partial \rho_{A}}\right)\right]
$$




$$
\ln \gamma_{S}^{P_{\text {er }}}=-\frac{B \pi}{k T}\left[\rho_{S} \varepsilon_{S S} \sigma_{S S}^{3}+\rho_{d} \varepsilon_{A S} \sigma_{A S}^{3}+3 \rho_{A t} \rho_{S} \varepsilon_{t S} \sigma_{t S}^{2}\left(\frac{\partial \sigma_{A S}}{\partial \rho_{S}}\right)\right]
$$

where the constant $B$ is taken as 0.2 to be consistent with the 'pure' amino acid case.

\section{The Cross Differential Relation for the Perturbation Theory}

According to thermodynamics, for the activity coefficients of the amino acid $\div$ electrolyte + water system, the following cross differential relation should be satisfied

$$
\left(\frac{\partial \ln \gamma_{A}}{\partial m_{s}}\right)_{T, m_{1}}=v\left(\frac{\partial \ln \gamma_{s}}{\partial m_{A}}\right)_{T, m_{s}}
$$

or using the definition of number density,

$$
\left(\frac{\partial \ln \gamma_{A}}{\partial \rho_{S}}\right)_{\tau, \rho_{1}}=v\left(\frac{\partial \ln \gamma_{z}}{\partial \rho_{A}}\right)_{T \cdot \rho_{s}}
$$

Combining eqs.(4-4) and (4-5) with eq.(D-2), we have

$$
\left(\frac{\partial \ln \gamma_{A}^{H S}}{\partial \rho_{S}}\right)_{T, \rho_{r}}=\left(\frac{\partial \ln \gamma_{S}^{H S}}{\partial \rho_{A}}\right)_{T \cdot \rho_{\mathrm{S}}}
$$

and

$$
\left(\frac{\partial \ln \gamma_{A}^{P_{e r}}}{\partial \rho_{S}}\right)_{T, \rho_{A}}=\left(\frac{\partial \ln \gamma_{S}^{P_{e r}}}{\partial \rho_{A}}\right)_{T, \rho_{S}}
$$

Eq.(D-3) is automatically satisfied according to the derivation of the activity coefficients of hard sphere mixture. Eq.(D-4) is satisfied according to the derivation of the perturbation activity coefficient and the mixing rules eqs.(4-27) and (4-28). In fact, it is easy to show that 
Appendices

$$
\begin{aligned}
\left(\frac{\partial \ln \gamma_{A}^{P e r}}{\partial \rho_{S}}\right)_{\rho_{s}}= & \left(\frac{\partial \ln \gamma_{S}^{P e r}}{\partial \rho_{s}}\right)_{\rho_{S}}= \\
& -\frac{B \pi}{k T} \varepsilon_{S S} \sigma_{A S}^{3}\left[1+\frac{9}{2} \rho_{A} \rho_{S} \delta^{(1)} \frac{\sigma_{A t}+\sigma_{S S}}{\sigma_{A S}}+\frac{3}{2}\left(\rho_{A} \rho_{S} \delta^{(1)}\right)^{2}\left(\frac{\sigma_{A t}+\sigma_{S S}}{\sigma_{A S}}\right)^{2}\right]
\end{aligned}
$$

Therefore, the equations used in this work satisfy the cross differential relation. 